\title{
Derechos colectivos y derechos políticos de los pueblos y nacionalidades del Ecuador: análisis de las elecciones 2013 en cinco cantones
}

\author{
Collective and Political Rights of Peoples and \\ Nationalities of Ecuador: Analysis of the 2013 \\ elections in five counties.
}

Richard Salazar Medina y Cristina Soler García

Recepción: 3 de junio de 2013

Aceptación: 27 de agosto de 2013

\section{Resumen}

El retorno a la democracia en el Ecuador (1978) permitió el fortalecimiento y trascendencia de los movimientos sociales. Uno de los elementos paradigmáticos de este proceso fue la autorización del voto a personas analfabetas, que en su gran mayoría eran indígenas, afrodescendientes y campesinos. El presente artículo, tras hacer una breve revisión histórica de la participación política de los pueblos de la diversidad cultural del país y sus actores en las últimas décadas, analiza el contexto constitucional y legal actual de los derechos políticos de los pueblos del Ecuador. Luego, a la luz del proceso electoral de febrero de 2013, analiza la posible existencia de una dinámica del voto frente a candidatos de las diversidades culturales en cinco cantones con alta autoidentificación indígena, afroecuatoriana o montubia. El trabajo muestra interesantes resultados y observaciones de gran utilidad para los tomadores de decisiones respecto de los instrumentos electorales, así como para las organizaciones de los pueblos del país e investigadores en la materia.

Palabras clave: derechos políticos, Estado plurinacional, Estado intercultural, elecciones, comportamiento electoral.

\begin{abstract}
The return to democracy in Ecuador (1978) allowed for the strengthening and development of social movements. One of the paradigmatic elements of this process was the extension of the right to suffrage to the illiterate, who were mostly indigenous people, Afro-Ecuadorians, or people from rural areas. Following a brief look at the history of political participation of different cultural groups of the country and their actors in recent decades, this article analyzes the current constitutional and legal context of the political rights of the peoples of Ecuador. Then, in light of the electoral process of February 2013, it analyzes the possible existence of a voting dynamic when there are candidates of diverse cultural groups, looking at five counties with high rates of self identification as being indigenous, Afro-Ecuadorian, or of the Montubio ethnicity. This work shows interesting results and very useful observations for those making decisions regarding electoral instruments, as well as for organizations of the peoples of Ecuador and researchers of this subject matter.
\end{abstract}

Keywords: political rights, plurinational State, intercultural State, elections, voting behavior. 


\section{Introducción}

1 retorno a la democracia en el Ecuador en 1978 resultó también el puente hacia nuevos procesos de fortalecimiento y trascendencia de los movimientos sociales. Además de las luchas históricas de los distintos movimientos y la consolidación de organizaciones de la diversidad cultural del país, el nuevo periodo -cuya transición empezó con la nueva Constitución, aprobada mediante referéndum en enero de 1978- realizó cambios fundamentales para la democracia y la ciudadanía. El tema, desde nuestra perspectiva, más importante de la Constitución de 1978 es que se otorga ciudadanía a las personas analfabetas, ya que la anterior Constitución (1967) establecía que eran ciudadanos ecuatorianos únicamente "los mayores de dieciocho años que saben leer y escribir y están, por tanto, en aptitud de ejercer los derechos políticos que establece la presente Constitución" (1967, Art. 21). Esto hoy en día nos parece algo impensable, inaceptable, pero efectivamente fue así hasta 1978, por lo cual la universalización explícita de la ciudadanía es un cambio paradigmático en la perspectiva política y sobre derechos civiles en el país. A partir de esto se hace un avance paradigmático en los derechos políticos de los ciudadanos ya que se permite el voto facultativo de las personas analfabetas:

El voto es universal, igual, directo y secreto, obligatorio para los que sepan leer y escribir y facultativo para los analfabetos. Tendrán derecho a voto los ecuatorianos que hubieren cumplido 18 ańos de edad y se hallen en goce de los derechos políticos (Constitución 1978¹ Art. 33).

1 La versión codificada por el Congreso Nacional en 1997 hace un aumento al primer Artículo en la calidad del Estado, incluyendo que es también "pluricultural y multiétnico". Más adelante en el mismo artículo, el Congreso Nacional incluye en dicha codificación de 1997 que "El idioma oficial y de relación intercultural es el castellano. El quichua y las demás lenguas indígenas son reconocidas dentro de sus respectivas áreas de uso y forman parte de la cultura nacional”(Art. 1). Por ello se recomienda, para no tener confusiones y entender la naturaleza de cada Constitución, revisar la versión original; en el caso de la Constitución de 1978 se puede revisar la versión codificada en 1984. 
Vale mencionar que se establece un nuevo mecanismo como complemento de la democracia representativa: la consulta popular que se lleva a cabo a través del referéndum; esta podía ser convocada por el Presidente de la República, por su iniciativa o por solicitud del Congreso Nacional, para consultar respecto de reformas constitucionales, de leyes en controversia entre el Ejecutivo y el Legislativo o por tratarse de "cuestiones de trascendental importancia para el Estado" (Constitución de 1978: Art. 35, 78 [p]).

No existía, sin embargo, ninguna alusión al reconocimiento de la diversidad cultural y los derechos que se derivan de ello. De hecho, es muy decidor que en el mismo Artículo 1 se determina que el único idioma oficial es el castellano y que "el quichua y las demás lenguas aborígenes forman parte de la cultura nacional", hablando de las lenguas de los pueblos indígenas como de un elemento más bien folclórico de la denominada cultura nacional. Por ello, lo que en sentido pragmático fue un avance importante que se denotaría con el paso de los años, para los pueblos indígenas, afroecuatorianos y campesinos fue la posibilidad de ejercicio de los derechos políticos, con el acceso al sufragio de personas analfabetas que eran entonces un importante segmento de la población; la cifra oficial en ese momento, según el Censo de Población y Vivienda de 1970 , era del $25,8 \%$ de analfabetismo ${ }^{2}$. Y es que por los conocidos e históricos elementos estructurales de exclusión, la mayor cantidad de analfabetos eran indígenas, afrodescendientes y campesinos, por lo que el derecho al voto fue principalmente, para ellos, una reivindicación histórica. Al mismo tiempo, en este proceso electoral (1978-1979) Jaime Hurtado, afrodescendiente de la provincia de Esmeraldas, fue electo Diputado siendo el primer afroecuatoriano en alcanzar el Congreso Nacional y el único perteneciente a los pueblos y nacionalidades ${ }^{3}$ hasta

2 Cfr. Ministerio de Educación-UNESCO (2009). En el Censo de Población y Vivienda de 1980 el porcentaje fue del $16,5 \%$, cifra más baja que la del censo anterior, pero igualmente importante y alarmante.

3 De manera abreviada usamos la denominación de pueblos y nacionalidades del Ecuador para referirnos a las comunas, comunidades, pueblos y nacionalidades indígenas, pueblo afroecuatoriano y pueblo montubio, que es la denominación que abarca toda la diversidad cultural del país 
ese momento. De hecho Hurtado, fundador del Movimiento Popular Democrático (MPD), no pudo presentarse como candidato a la Presidencia de la República en estos comicios porque su agrupación política, el MPD, no logró la inscripción como partido. Como vemos, este fue definitivamente un momento de ruptura para la democracia respecto de los pueblos y nacionalidades del Ecuador.

Bastante agua ha corrido desde entonces: para empezar, ventajosamente, la tasa de analfabetismo ha bajado al 6,8\% según el último Censo de Población y Vivienda (INEC, 2010); la educación es pilar vital para la democracia y el ejercicio de los derechos. Por otra parte, hoy los pueblos del Ecuador cuentan con un escenario jurídico mucho más auspicioso; basta citar los derechos colectivos y la definición del Ecuador como un Estado intercultural y plurinacional.

Pero, respecto de los derechos políticos de los pueblos y nacionalidades, ¿cómo ha evolucionado el contexto?, ¿existe igualmente un escenario propicio, como los elementos constitucionales de administración y política pública?, más aún, ¿̨los pueblos y nacionalidades del Ecuador han desarrollado -o no- una suerte de lealtad en el voto con sus representantes, que permita afianzar sus intereses y agendas en la vida política y el acceso al poder, o tienen más bien lealtad a partidos y proyectos políticos independientemente de su filiación a los pueblos de la diversidad?, ¿cómo se dibuja la representatividad de pueblos y nacionalidades, de su agenda, de sus intereses y necesidades estratégicas y específicas?, ¿tiene ya el Estado mecanismos para que esa representatividad se dé plenamente?

El objetivo del presente estudio es, en primer lugar, analizar el contexto constitucional y legal actual con respecto a los derechos políticos de los pueblos y nacionalidades indígenas, pueblo afroecuatoriano y pueblo montubio. Se realiza una breve revisión histórica desde 1978 hasta el presente, para pasar al análisis de fondo que es el del contexto

y que forman parte del Estado ecuatoriano, único e indivisible, según la Constitución vigente (Art. 56). Estos son además quienes son beneficiarios de los Derechos Colectivos (Art. 57-59). En lo posterior usaremos de manera general la denominación pueblos del Ecuador con esta misma significación. 
actual y los elementos relevantes de los dos cuerpos legales fundamentales en este sentido: la Constitución vigente (2008) y la Ley Orgánica Electoral y de Organizaciones Políticas (2009), más conocida como Código de la Democracia. Dicho estudio se realiza no solo sobre la base de los artículos que tienen que ver con el sufragio, sino que incluye aquellos criterios que determina la Constitución y que se relacionan con la democracia representativa, participativa y comunitaria. Todo ello para tener claro el marco de los derechos políticos al presente y sus connotaciones jurídicas y prácticas.

En segundo lugar, a la luz del proceso electoral de febrero de 2013, se analiza la existencia o no de una relación -o dinámica- entre el voto de los miembros de los pueblos y nacionalidades indígenas, pueblo afrodescendiente y pueblo montubio con los candidatos que se autoidentifican como pertenecientes a cada una de estas diversidades culturales. Para ello, se realiza una aproximación a los resultados electorales en cinco cantones de cinco provincias del país pertenecientes a las tres regiones continentales -Costa, Sierra y Amazonía-, mostrando al menos un ejemplo de cada uno de los pueblos -indígena, afrodescendiente y montubio- (en el caso indígena se contrastan nacionalidades de la Sierra y de la Amazonía). Cada uno de estos cantones fue seleccionado con relación a los datos de autoidentificación cultural-étnica reflejados en el Censo de Población y Vivienda (INEC, 2010)4 . Los cantones de los que se estudiaron los resultados electorales son los siguientes: San Lorenzo, cantón de alta población y autodefinición afroecuatoriana en Esmeraldas; Salitre, autoproclamado "la capital mundial de los montubios", en la provincia del Guayas; Guamote, con alta presencia y autodefinición de kichwas de la Sierra, en Chimborazo; cantón Arajuno, con población mayoritariamente kichwa de la Amazonía, en la provincia de Pastaza; y el cantón Taisha, con una alta presencia de habitantes que se autodefinen de la nacionalidad shuar, en Morona Santiago. El criterio de selección de los cantones, además de pertenecer a los tres pueblos con derechos colectivos del país y de encontrarse en las tres re-

4 Los casos fueron seleccionados en consenso con el Instituto de la Democracia. 
giones naturales, fue que el porcentaje de población relacionado con un pueblo y/o nacionalidad concreta (indígena, afroecuatoriano o montubio) fuera superior a dos tercios del total (66,7\% de la población). Este porcentaje surge del criterio constitucional que permite conformar jurisdicciones político administrativas donde haya presencia de pueblos y nacionalidades - luego de un referéndum que confirme la voluntad de sus habitantes-, circunscripciones territoriales interculturales, como régimen especial (Constitución de 2008, Art, 60 y 2575).

Cabe mencionar que el análisis de los casos elegidos no puede tomarse para hacer generalizaciones sobre ninguna de las tendencias que se encuentren en cada caso, ni a nivel de regiones (Costa, Sierra, Amazonía) ni del pueblo que se trate; no obstante, la información obtenida resulta útil para ilustrar las dinámicas electorales de pueblos y nacionalidades del Ecuador, así como para propiciar la reflexión y la investigación en profundidad, a futuro, sobre diferentes cuestiones respecto de los derechos políticos de los pueblos y nacionalidades, así como de las herramientas institucionales (electorales) frente a la diversidad cultural y su representación en las dignidades de elección popular, bajo la perspectiva constitucional de equidad, inclusión y participación. El análisis de estos resultados puede ser de gran utilidad para los tomadores de decisiones respecto de los instrumentos electorales, para volverlos incluyentes y acordes a la perspectiva constitucional de derechos de las diversidades del país, particularmente en lo que respecta a derechos políticos; de la misma manera, resulta de utilidad para los pueblos y nacionalidades y sus organizaciones, así como para investigadores en la materia.

Adicionalmente, este estudio nos permitirá observar qué incidencia podría tener un posible fenómeno de lealtad electoral de la diversidad cultural en el fortalecimiento de los derechos colectivos, así como la proyección e incidencia que ello adquiere en la participación activa en la vida política del país y en la construcción de las políticas públicas.

5 "Las parroquias, cantones o provincias conformados mayoritariamente por comunidades, pueblos o nacionalidades indígenas, afroecuatorianos, montubios o ancestrales podrán adoptar este régimen de administración especial, luego de una consulta aprobada por al menos las dos terceras partes de los votos válidos" (Constitución de 2008: Art. 257). 


\section{El contexto actual de los pueblos y nacionalidades}

\section{Un repaso de la historia reciente: del retorno de la democracia al presente}

El primer candidato a la Presidencia de la República por parte de los pueblos y nacionalidades en la historia del Ecuador fue el afrodescendiente Jaime Hurtado, en el año 1984, cuando quedó en cuarto lugar por delante de candidatos como Francisco Huerta Montalvo, Julio César Trujillo y Manuel Salgado. Esta fue la apertura del camino de la participación activa de los pueblos de la diversidad cultural en la vida política del Ecuador la misma que, en adelante, sería cada vez más fuerte.

El nuevo periodo democrático en el país, desde 1978, fue un momento de efervescencia de los movimientos sociales y de la exigencia de los derechos, particularmente de los pueblos y nacionalidades; esto fue el colofón de una larga trayectoria de luchas desde épocas coloniales y la temprana República. Durante la segunda mitad del pasado siglo XX, emergieron diversos movimientos indígenas con una fuerza inusitada en el país y en varios lugares de América Latina; en el caso del Ecuador, un nivel de organización que se fortaleció y fecundó importantes luchas y logros desde la década de 1960.

El camino ha sido largo. De esas primeras expresiones en pro del reconocimiento cultural, así como del fortalecimiento de organizaciones sociales, la década de 1980 marca un hito. Se logra la conformación de la Confederación de Nacionalidades Indígenas del Ecuador (CONAIE), que tiene en su seno organizaciones filiales de las tres regiones naturales del país: la Confederación de Nacionalidades y Pueblos Indígenas de la Costa Ecuatoriana (CONAICE), en la Costa; la Confederación Kichwa del Ecuador (ECUARUNARI), en la Sierra; y la Confederación de Nacionalidades Indígenas de la Amazonía Ecuatoriana (CONFENIAE), en la Amazonía. En esta última región hay que citar, como punto aparte, a la Organización de Pueblos Indígenas del Pastaza (OPIP) que, pese a formar parte de la CONFENIAE, desde la década de 1970 tuvo un liderazgo indiscutible en la Amazonía y también en las movilizaciones 
de 1990 y 1992. Asimismo, hay que mencionar a la Confederación de Organizaciones Campesinas, Indígenas y Negras (FENOCIN), y la histórica Federación Ecuatoriana de Indios (FEI), que ya tenían una larga trayectoria. Entre las organizaciones afroecuatorianas cabe nombrar a la Comarca Afroecuatoriana del Norte de Esmeraldas (CANE), la Federación de Comunidades y Organizaciones Negras de Imbabura y Carchi (FECONIC), Federación de Organizaciones y Grupos Negros de Pichincha (FOGNEP,) Coordinación Nacional de Mujeres Negras (CONAMUNE), Consejo de la Unidad Afroecuatoriana (CONAUE), entre otras de importancia. $\mathrm{Y}$ en este orden diversas organizaciones campesinas del país.

La principal diferencia entre estos movimientos y las organizaciones de la CONAIE es que los movimientos reclamaban no únicamente un tratamiento igualitario en cuestión de derechos en la sociedad, sino el reconocimiento de sus costumbres, idiomas, modos de organización y de conocimiento, manejo territorial, ritos, cosmovisión, etc. En resumen, exigían el reconocimiento de su cultura y un espacio de genuina participación, no solo como individuos con derechos sino como pueblos pertenecientes al país, pero con sus propias formas culturales. Es decir, se pasa de la resistencia a la exigencia de derechos y a tener un país que los incluya en sus procesos. Pedían, entonces, que el Estado adapte su administración para que los pueblos de la diversidad cultural pudiesen desarrollarse sin dejar de ser quienes son, sin tener que asimilarse a la cultura dominante que se plasmaba en el Estado-nación, de matriz monocultural, como ya se ha mencionado en la introducción de este texto.

Es así que, en la teoría política y en las organizaciones sociales, empiezan a surgir nuevas propuestas tanto para definir a los grupos étnicos y movimientos emergentes como a las nuevas formas de Estado y sociedad a la que se aspiraba: ciudadanía diferenciada, Estados pluriculturales, multiétnicos, plurinacionales, interculturales, que han sido ya recogidas en las constituciones de algunos países latinoamericanos. Estas definiciones, particularmente la de interculturalidad, son muy vanguar- 
distas ya que van más allá del reconocimiento de las diferentes culturas, pues hacen referencia a una interrelación y participación en equidad. Varias de estas definiciones han suscitado polémicas, especialmente el concepto de nacionalidades indígenas y su consecuente propuesta del Estado plurinacional, formalizada por el movimiento indígena ${ }^{6}$ ecuatoriano en la década de 1980. Hechos fundamentales en este periodo son el levantamiento indígena de 1990, que por su trascendencia y fortaleza es seguramente el acto de resistencia y rebelión popular más importante de las últimas décadas; y la marcha de los pueblos y nacionalidades de 1992, por los 500 años de la denominada resistencia pacifica.

Estas luchas y el fortalecimiento de organizaciones políticas y sociales fueron teniendo un importante afianzamiento a nivel local, particularmente en algunas provincias de la Sierra y la Amazonía. Es así que, en 1992, es electo, por primera vez en la historia del Ecuador y de América Latina, un Alcalde indígena en Guamote, provincia del Chimborazo: Mariano Curicama, quien fue reelecto y posteriormente fue escogido para Prefecto provincial de Chimborazo (2005), cargo en el que también fue ratificado en una segunda ocasión y que ejerce hasta el presente. Asimismo en Imbabura, Cotacachi, el indígena Auki Tituaña fue designado como Alcalde en 1996, cargo para el cual fue reelegido en dos oportunidades; su sucesor y actual Alcalde, Alberto Anrango, también indígena perteneciente a la FENOCIN, organización que efectivamente tiene su origen en este cantón de Imbabura.

Esto se da porque el movimiento indígena en el Ecuador se fortaleció y creció contundentemente en las décadas de 1980 y 1990. Para 1995, la CONAIE decide la creación de un movimiento político para que represente los intereses de los pueblos indígenas y participe activamente en la política electoral del país, buscando los espacios de poder como camino para lograr la equidad y cambios estructurales; este es el Movimiento de Unidad Plurinacional Pachakutik (MUPP). Esta orga-

6 Cuando decimos movimiento indígena nos referimos a todas las organizaciones indígenas de primero, segundo y tercer grado, y a las confederaciones que las representan, entre las que figuran las arriba citadas entre otras. 
nización política ha tenido hasta la actualidad una preponderante participación en la política nacional, haciendo que surjan figuras políticas indígenas que tienen incidencia todavía en el presente; entre ellas podemos mencionar los nombres de Luis Macas, Diana Atamaint, Lourdes Tibán, Nina Pacari, Carlos Viteri (hoy del movimiento PAIS); los ya mencionados Mariano Curicama -expulsado en 2012 por su alianza desautorizada con el Movimiento PAIS-, Auki Tituaña -expulsado en 2012 por su alianza con el partido CREO para presentarse como binomio del candidato presidencial Guillermo Lasso-, entre otros.

Por otra parte también estaba la FENOCIN que actuó muy cercana siempre al Partido Socialista, donde florecieron nombres de políticos como Alberto Anrango - hoy Alcalde de Cotacachi en alianza con el Movimiento PAIS-, Segundo Andrango -actualmente Embajador del Ecuador en la República de El Salvador-, Pedro de la Cruz -ex Asambleísta constituyente, luego Asambleísta nacional de 2009 a 2013 y hoy Presidente del Parlamento Andino, en alianza con Movimiento PAIS-, Manuela Cobacango Consejera del Consejo Nacional Electoral entre 2008 y 2011-, entre otros.

Dichas luchas dan como resultado un logro histórico cuando en la Constitución de 1998 se incluye en su primer artículo las condiciones de pluriculturalidad y multietnicidad como características del Estado:

\begin{abstract}
Art. 1.- El Ecuador es un Estado social de derecho, soberano, unitario, independiente, democrático, pluricultural y multiétnico. [...] El Estado respeta y estimula el desarrollo de todas las lenguas de los ecuatorianos. El castellano es el idioma oficial. El quichua, el shuar y los demás idiomas ancestrales son de uso oficial para los pueblos indígenas, en los términos que fija la ley... (Constitución de 1998).
\end{abstract}

Asimismo, en dicha Constitución se logra introducir los derechos colectivos reconocidos para los pueblos indígenas (Art. 8477) y negros o afro-

7 "El Estado reconocerá y garantizará a los pueblos indígenas, de conformidad con esta Constitución y la ley, el respeto al orden público y a los derechos humanos, los siguientes derechos colectivos:

1. Mantener, desarrollar y fortalecer su identidad y tradiciones en lo espiritual, cultural, lingüístico, social, político y económico. 2. Conservar la propiedad imprescriptible de las tierras comu- 
ecuatorianos (Art. 85 $5^{8}$, que recogen lo que contempla la Declaración de la OIT (1989).

Este fue el elemento institucional para la legitimación de la existencia del Consejo de Desarrollo de Nacionalidades y Pueblos del Ecuador (CODENPE), que se concretó luego de la aprobación de esta Constitución (Decreto Ejecutivo N. $\left.{ }^{\circ} 386\right)^{9}$, que incluía también a los pueblos afroecuatorianos en principio, hasta que en 2005 se creó la Corporación de Desarrollo Afroecuatoriano (CODAE) (Decreto Ejecutivo N.o 244). En 2001 se creó el Consejo de Desarrollo del Pueblo Montubio de la Costa Ecuatoriana y de las Zonas Subtropicales de la Región Litoral (CODEPMOC) (Decreto Ejecutivo N. $\left.{ }^{\circ} 1394\right)$. Estos son los tres consejos de pueblos y nacionalidades que existen hasta la actualidad y que, conjuntamente, pasarían a formar parte del Consejo de Igualdad de Temas Étnicos (Constitución de 2008, Art. 156-157).

nitarias, que serán inalienables, inembargables e indivisibles, salvo la facultad del Estado para declarar su utilidad pública. Estas tierras estarán exentas del pago del impuesto predial. 3. Mantener la posesión ancestral de las tierras comunitarias y a obtener su adjudicación gratuita, conforme a la ley. 4. Participar en el uso, usufructo, administración y conservación de los recursos naturales renovables que se hallen en sus tierras. 5. Ser consultados sobre planes y programas de prospección y explotación de recursos no renovables que se hallen en sus tierras y que puedan afectarlos ambiental o culturalmente; participar en los beneficios que esos proyectos reporten, en cuanto sea posible y recibir indemnizaciones por los perjuicios socioambientales que les causen. 6 . Conservar y promover sus prácticas de manejo de la biodiversidad y de su entorno natural. 7. Conservar y desarrollar sus formas tradicionales de convivencia y organización social, de generación y ejercicio de la autoridad. 8. A no ser desplazados, como pueblos, de sus tierras. 9. A la propiedad intelectual colectiva de sus conocimientos ancestrales; a su valoración, uso y desarrollo conforme a la ley. 10. Mantener, desarrollar y administrar su patrimonio cultural e histórico. 11. Acceder a una educación de calidad. Contar con el sistema de educación intercultural bilingüe. 12. A sus sistemas, conocimientos y prácticas de medicina tradicional, incluido el derecho a la protección de los lugares rituales y sagrados, plantas, animales, minerales y ecosistemas de interés vital desde el punto de vista de aquella. 13. Formular prioridades en planes y proyectos para el desarrollo y mejoramiento de sus condiciones económicas y sociales; a un adecuado financiamiento del Estado. 14. Participar, mediante representantes, en los organismos oficiales que determine la ley. 15. Usar símbolos y emblemas que los identifiquen" (Constitución de 1998, Art. 84)

8 "El Estado reconocerá y garantizará a los pueblos negros o afroecuatorianos, los derechos determinados en el artículo anterior, en todo aquello que les sea aplicable" (Constitución de 1998, Art.85)

9 No hay que perder de vista, sin embargo, que esto fue una redefinición de la Secretaría de Pueblos Indígenas que creó el Presidente Sixto Durán Ballén en 1994, que posteriormente en la Presidencia interina de Fabián Alarcón, en 1997, fue redefinido como Consejo de Planificación y Desarrollo de los Pueblos Indígenas y Negros (CONPLADEIN). 
En este escenario, no hay que perder de vista que la CONAIE y el movimiento indígena fueron un puntal fundamental para la presión, movilizaciones y consecuente derrocamiento del Presidente Jamil Mahuad en el año 2000, y que quien la presidía en ese entonces, el indígena de Pastaza, Antonio Vargas, se postuló a la Presidencia de la República en 2002 por el Movimiento Amauta Jatari. Posteriormente, en el año 2006, fue candidato a la Presidencia por Pachakutik el histórico líder indígena Luis Macas.

Y el colofón de estas largas luchas y participación de las organizaciones de los movimientos indígena, afroecuatoriano y ahora también del pueblo montubio, se dio en la Asamblea Constituyente de Montecristi (2007-2008) a partir de la cual se consagraron una serie de derechos y principios constitucionales de política pública, además de los derechos colectivos, algunos de los cuales analizaremos en el siguiente acápite, revisando aquellos que se relacionan con los derechos políticos de los pueblos y nacionalidades.

\section{La Constitución de 2008}

El contexto en el cual realizamos el presente análisis es ciertamente particular. En el pasado nunca había existido en el país una legislación tan garantista en torno al respeto, la promoción y revitalización de las diversidades culturales y sus manifestaciones como en la Constitución vigente (2008). Sin embargo, esto no quiere decir que el Ecuador se enmarque en un contexto de tolerancia a la diversidad. Como sabemos, el Ecuador viene de una historia de marcado racismo y exclusión aún no superados. Pero la Constitución de 2008 abrió un importante camino para estas comunidades, al reconocer las viejas luchas de los pueblos ecuatorianos $-\mathrm{y}$ con ello la plurinacionalidad-, promoviendo la interculturalidad, elemento que constituye el mejor camino para poder desarrollarse con transparencia, autenticidad y equidad cultural, social y territorial. 
La actual Constitución (2008) determina una completa inclusión y la posibilidad de una participación en equidad para los pueblos y nacionalidades en la toma de decisiones, así como en la vida política y en las políticas públicas del país. Es en ese escenario que realizamos este análisis, el de la representatividad de la diversidad de pueblos ${ }^{10}$, a partir del ejercicio de los derechos políticos, particularmente de la democracia representativa manifestada en las pasadas elecciones de febrero de 2013. Revisamos, en primera instancia, los elementos de la Constitución de los pueblos del Ecuador.

La Constitución vigente (2008) reconoce al Ecuador como un "Estado constitucional de derechos y justicia, democrático, soberano, independiente, unitario, intercultural, plurinacional y laico" y adicionalmente determina que "[l] a soberanía radica en el pueblo, cuya voluntad es el fundamento de la autoridad” (Art. 1). Que la soberanía radique en el pueblo, en un Estado que se ha reconocido previamente como diverso e intercultural, es un hecho fundamental en la perspectiva de la democracia, tanto representativa como directa y comunitaria.

Por otra parte, el incluir la condición de interculturalidad y plurinacionalidad constituye una ruptura epistemológica con la definición del Estado-nación liberal que, pese a los preceptos con que fue mentalizado -libertad, ciudadanía, equidad, derechos civiles y políticos-, definitivamente ha fracasado en los lugares de mayor diversidad cultural por su búsqueda de la homogeneidad de los ciudadanos. De hecho, en el pasado se hablaba de lo indígena, tanto en la política como en sectores

10 Usamos el término pueblo para designar a grupos y comunidades históricamente conformados y con formas de organización e institucionalidad de legitimidad propia a su comunidad, comprendiendo elementos culturales particulares y diferenciados que pueden incluir idioma, religión, estética y todos los rasgos propios de una cultura antropológicamente concebida. Se usa esta nomenclatura por considerarla más apropiada y genérica para lo que otros autores de las ciencias política y antropológica llaman etnias, naciones, nacionalidades o culturas, que pueden generar conflictos en las interpretaciones jurídicas o con la autodefinición. Por ejemplo, en varios países los indígenas rechazan que se les designe como etnias por considerarlo peyorativo, al percibir una connotación no de sujetos, de personas, sino de objetos de estudio. Por otra parte, algunos autores hablan de minorías étnicas para denominar los grupos nacionales de los países de los inmigrantes en los países receptores. Cabe aclarar que esta definición es también apropiada e incluyente con los pueblos afroecuatoriano y montubio que son también beneficiarios de los derechos colectivos. 
administrativos e incluso académicos como un problema (el problema indigena), es decir como un escollo, una piedra en el zapato del Estado liberal ${ }^{11}$.

Pero el fracaso de las políticas unificadoras, la elocuencia de la diversidad (CODENPE reconoce catorce nacionalidades y dieciocho pueblos en el Ecuador), así como la lucha de los pueblos del Ecuador, hacían imposible continuar sin una definición y sin una acción concreta del Estado. Es por ello que se recurrió a la creación de CODENPE, CODAE y CODEPMOC que, si bien fue un paso importante e ineludible, de todas maneras focaliza y hace que los pueblos indígenas, afroecuatorianos y montubios sean tratados como una minoría. El Estado debe crear una ingeniería institucional en todas sus funciones que permita una verdadera interculturalidad institucional y participación en la decisión y beneficios de las políticas públicas, obras y presupuestos, acorde con las necesidades y aspiraciones de los pueblos en todo el territorio.

Pero, ¿es suficiente la visibilización y la posibilidad de desarrollarse en un territorio a partir de sus propias formas culturales y de organización? Definitivamente, no. Hace falta una participación directa en el ejercicio de los derechos políticos, no únicamente ejerciendo universalmente el voto, sino a través de candidatos de los pueblos y nacionalidades que representen sus intereses, sus problemas y necesidades, para que estos puedan ser efectivamente resueltos en las políticas de las distintas formas de gobierno. Y para esto, es necesario que el sistema electoral y sus herramientas favorezcan y garanticen la participación y representación de los pueblos. De no cristalizarse esto, la inclusión, la equidad y las acciones afirmativas no pasarán de ser un enunciado constitucional.

En la Constitución vigente (2008) existen algunos elementos que fortalecen y determinan esta perspectiva que repasaremos brevemente.

11 Nos referimos al Estado liberal desde la perspectiva del liberalismo igualitario de la filosofía política y no al liberalismo (y mucho menos al neoliberalismo) económico. Según esta noción, el individuo es la unidad última del valor moral, teniendo cada persona un estatus moral igual, por lo cual debe ser tratada por el Gobierno con igual consideración y respeto (Kymlicka, 1996; Torbisco Cassals, 2009). 
Estos son los mencionados derechos colectivos, la participación ciudadana y la democracia comunitaria. También cabe destacar el Sumak Kawsay, los consejos nacionales de igualdad y la posibilidad de construir regímenes especiales de circunscripciones territoriales interculturales, que tienen que ver con el régimen de desarrollo del país y las políticas públicas planificadas con pertinencia plural y territorial. Sin embargo, estos serían elementos de otra reflexión.

a) Los derechos colectivos: el reconocimiento pleno de los derechos colectivos de los pueblos indígenas, afroecuatorianos y montubios es un paso determinante para construir la interculturalidad y los derechos políticos. La Constitución es auspiciosa y enumera veintiún derechos que, seguramente, representan el más copioso número de derechos colectivos que reconozca ninguna otra Constitución. En lo medular, se reconocen los distintos pueblos, su autodeterminación cultural, los territorios de los pueblos indígenas cuya propiedad es imprescriptible y exenta de tasas tributarias; el derecho a crear y fusionar circunscripciones territoriales en las jurisdicciones del ordenamiento territorial ecuatoriano (parroquias, cantones y provincias); el reconocimiento a la justicia indígena en el marco del respeto a los derechos humanos; el derecho de ser consultados respecto a actividades extractivas en sus territorios, así como respecto de leyes que les afecten; y el compromiso del Estado a no realizar actividades extractivas en territorios de pueblos en aislamiento voluntario.

Con referencia a lo que nos atañe específicamente en este análisis, los derechos colectivos determinan:

Construir y mantener organizaciones que los representen, en el marco del respeto al pluralismo y a la diversidad cultural, política y organizativa... (Art. 57, inciso 15).

Participar mediante sus representantes en los organismos oficiales que determine la ley, en la definición de las políticas públicas que les conciernan, así como en el diseño y decisión de sus prioridades en los planes y proyectos del Estado (Art. 57, inciso 16). 
Si bien éste último hace alusión más específicamente a las políticas públicas y a los consejos nacionales de igualdad, vale la pena citarlo porque se trata de la participación de sus representantes y esto bien puede ser también en los espacios de elección popular.

Adicionalmente, la trascendencia de los derechos colectivos también está relacionada con un cambio epistemológico en la concepción de los derechos de forma distinta a lo individual, es decir, colectiva. Entre los indígenas de todo el continente americano (y muchas otras culturas y pueblos de otras latitudes no occidentales), su cosmovisión y prácticas de vida, la unidad moral no es el individuo, como ocurre en los Estados y las democracias liberales, donde el sujeto de derechos es siempre universal e irrenunciablemente del individuo (o ciudadano/a) en igualdad de condiciones con todos los otros ciudadanos/as. En sus culturas la unidad moral es la comunidad, todo es comunitario, nunca individual. De ahí que lo peor que puede sucederle a un indígena es que lo excluyan o expulsen de su comunidad. Esto es de difícil comprensión para quienes pertenecemos a una matriz cultural occidental y a una tradición liberal de los derechos, de modo que cada individuo decide libremente su voto y en una misma familia se pueden contar votos distintos. Es por ello que hay un choque cultural cuando se ve que en los procesos electorales muchas comunidades indígenas que mantienen sus usos, se deciden colectivamente al o los candidatos por quienes se va a votar, y ciertamente todos votan de la manera dictaminada por la asamblea; en el caso de que en dicha junta exista algún voto distinto, se busca al 'culpable' y se lo sanciona.

Precisamente, es esta perspectiva distinta de la forma de percibir lo que llamamos democracia y ciudadanía, lo que hace una tarea impostergable definir, trabajar y ejecutar la democracia comunitaria, también determinada en la Constitución y que analizamos después de la participación ciudadana que es justamente aquella que la alude.

b) La participación ciudadana: otra de las novedades de la Constitución vigente es el estatuto que se le confiere a la participación ciudadana, que da a los ciudadanos la posibilidad de intervención en las decisiones de interés común, así como en el control social. Específicamente: 
Los ciudadanas y ciudadanos, en forma individual y colectiva, participarán de manera protagónica en la toma de decisiones, planificación y gestión de los asuntos públicos y en el control popular de las instituciones del Estado y la sociedad, y de sus representantes en un proceso permanente de construcción del poder ciudadano. La participación se orientará por los principios de igualdad, autonomía, deliberación pública, respeto a la diferencia, control popular, solidaridad e interculturalidad.

La participación de la ciudadanía en todos los asuntos de interés público es un derecho, que se ejercerá a través de los mecanismos de la democracia representativa, directa y comunitaria ${ }^{12}$ (Art. 95).

La participación, vista así, significa entonces no únicamente estar presentes sino participar de manera efectiva, incluyendo los criterios y voluntades de todas las diversidades, sin niveles de subordinación, sino en plena horizontalidad.

Vale la pena citar los principios de la participación aquí determinados: igualdad, autonomía, deliberación pública, respeto a la diferencia, control popular, solidaridad e interculturalidad. Y de estos subrayar la igualdad, el control popular y la interculturalidad, que tienen que ver directamente con la perspectiva de la participación plural de los ciudadanos en su diversidad, en este caso, de los pueblos y nacionalidades.

Sin embargo, lo más importante de los derechos políticos, para nuestro análisis, es que se determinan tres tipos distintos de democracia: la representativa, a partir de la cual se eligen las autoridades nacionales y locales; la directa, que es aquélla relacionada con los referéndum solicitados por el pueblo para temas que le son importantes y de interés común, demostrado a través de la recolección de un porcentaje de firmas del padrón electoral; y la democracia comunitaria, la absoluta novedad y que está por definirse, promover y ejecutar desde la perspectiva institucional. c) La democracia comunitaria: representa una gran novedad expresada en la Constitución de 2008. Esta sería, según el mencionado Artículo 95, complementaria a la democracia representativa y a la democracia

12 El énfasis es de los autores. 
participativa o directa, a partir de la visión plural y de la realidad de las prácticas de la variedad de pueblos en el multicultural territorio del Ecuador. Asimismo se relaciona con el inciso ya revisado de los derechos colectivos, de

... constituir y mantener organizaciones que los representen en el marco del pluralismo y la diversidad política, y la obligación del Estado ecuatoriano de reconocer y promover todas las formas de expresión y organización (Art. 57, inciso 15).

Aquí, el Consejo Nacional Electoral (CNE) y la Asamblea Nacional son actores protagónicos de este derecho y pueden pensar en una legislación específica para la creación de organizaciones políticas de pueblos y nacionalidades o de regulaciones específicas a este respecto dentro de toda organización política; por otra parte, bien puede pensarse en una ley de cuotas a favor de las diversidades culturales, así como la existente ley de cuotas para el respeto a la paridad y alternabilidad entre hombres y mujeres en la conformación de listas.

Pero esto no es todo, es necesario reflexionar en torno a la democracia comunitaria y, en el Ecuador, aún no se ha dado esta reflexión. Históricamente han existido -y existen hasta la actualidad- formas de organización, decisión y delegación de autoridades en los territorios habitados por los pueblos y nacionalidades del país. De hecho, estas formas están relacionadas con el consenso colectivo y con otras formas culturales de asunción de responsabilidades gubernativas, según dictan los usos y costumbres locales. Estas funcionan en el contexto comunitario y tienen legitimidad hasta el presente y, a decir verdad, generalmente (hasta cuando chocan y/o se contaminan con dinámicas clientelares ajenas a su contexto) funcionan de manera eficiente en la administración territorial local en sectores rurales del país. En efecto, se puede observar en el caso ecuatoriano varias dinámicas comunitarias de administración de territorio, por la ausencia del Estado, que tienen gran legitimidad y éxito en estos sectores de las tres regiones naturales. Basta citar las juntas de agua (o de regantes) en el callejón interandino. 
Es por ello que no puede sino ser un acierto la inclusión de la democracia comunitaria en la Constitución. Ahora solo resta aplicarla y para ello, afortunadamente por mandato de la misma Constitución, se cuenta en el Ecuador con el CNE, que no es únicamente un organismo electoral sino parte de una de las cinco funciones del Estado (Ejecutivo, Legislativo, Judicial, Electoral y Participación Ciudadana). Ello le confiere la rectoría de la democracia en el país, no únicamente en los procesos electorales, lo cual es una enorme responsabilidad. Dentro de esta responsabilidad está el reconocer, precautelar, dar un paraguas constitucional y, con ello, apoyar a estas formas que funcionan en la práctica, aprehendiendo incluso elementos de las mismas. Es decir, dar paso a la democracia intercultural.

Esto nos lleva indefectiblemente a la discusión de la ciudadanía y sus derivaciones. ¿Es el concepto de ciudadanía liberal -donde cada persona hace ejercicio individual de sus derechos y obligaciones frente al Estado-suficiente en el contexto ecuatoriano y latinoamericano? Y es justamente allí donde cobran sentido los distintos mecanismos existentes para permitir la participación equitativa en la diferencia y su aplicación en el Estado. En esta perspectiva no solo son un reconocimiento de la pluralidad, sino la puerta para lograr el Estado intercultural, que es como se define hoy el Ecuador. Por ende, requerimos una nueva percepción de la ciudadanía con matices para la pluralidad de cosmovisiones que, para nuestro caso, no sería únicamente una ciudadanía diferenciada como proponen varios autores (Kymlicka, 2009), sino una ciudadanía intercultural. Para esto necesitamos ser innovadores y atrevernos a nuevas definiciones, coherentes con el marco constitucional que ya incluye estos factores; pensar en nuevas ingenierías institucionales y herramientas apropiadas para la participación en equidad, también en el acceso al poder y en los mecanismos para lograr dicho acceso. 


\section{El Código de la Democracia}

La Ley Orgánica Electoral y de Organizaciones Políticas (2009), más conocida como Código de la Democracia, es la que desarrolla las garantías establecidas en la Constitución de la República respecto de los derechos políticos y de participación de la ciudadanía, así como la independencia y autonomía de los órganos y organismos electorales, la transparencia y legitimidad del gasto y la propaganda electoral.

En términos generales debe decirse que el Código de la Democracia no contiene aún elementos de la democracia comunitaria, ni contempla elementos para la participación plena de la diversidad de pueblos y nacionalidades del Ecuador. No obstante, hemos revisado un extracto de elementos que se mencionan útiles para la temática que nos convoca en este análisis.

En su artículo primero (Código de la Democracia, 2009), reitera el Art. 1 de la Constitución de 2008, reconociendo que el Ecuador es un Estado intercultural, plurinacional y laico. Asimismo, determina que "[1]a soberanía radica en el pueblo, cuya voluntad es el fundamento de la autoridad". Como ya habíamos anotado, el hecho de que la soberanía radique en el pueblo, en un Estado que se ha reconocido previamente como diverso, plural e intercultural, es fundamental en la perspectiva de la democracia, tanto representativa como directa y comunitaria y tiene, por tanto, una connotación que amerita herramientas institucionales y legales igualmente acopladas a esta diversidad, para respetar dicha soberanía. Es decir, siendo el pueblo en su diversidad el que ha de determinar el fundamento de las autoridades de elección popular, deben existir mecanismos electorales lo suficientemente eficaces para lograr este mandato. Esto es precisamente aquello a complementar en él.

En su artículo segundo, cita los derechos de los/as ciudadanos/as ecuatorianos/as, donde resulta claro que hay elementos de la democracia particularmente representativa y directa, pero faltan aquellos de la democracia comunitaria. Los derechos son: "elegir y ser elegidos; participar en los asuntos de interés público; presentar proyectos de ini- 
ciativa popular normativa; ser consultados; revocar el mandato de las autoridades de elección popular; conformar partidos y movimientos políticos; afiliarse y desafiliarse de los partidos políticos; adherirse a los movimientos políticos; participar en las decisiones de las organizaciones políticas; intervenir como veedores u observadores en los procesos electorales y exigir la rendición de cuentas y la transparencia de la información de los sujetos políticos”.

Para este análisis es importante citar el Art. 6 del Código de la Democracia (2009):

La Función Electoral tiene como finalidad asegurar que las votaciones y los escrutinios traduzcan la expresión auténtica, libre, democrática y espontánea de la ciudadanía y sean el reflejo oportuno de la voluntad del electorado expresada en las urnas por votación directa y secreta.

Adicionalmente lo expresado en el Art. 10:

La ciudadanía expresa su voluntad soberana, entre otros, por medio del voto popular que será universal, igual, periódico, directo, secreto y escrutado públicamente, que se manifiesta en los tiempos, condiciones, y bajo las normas que esta ley señala para garantizar la permanencia y el perfeccionamiento de la democracia.

Finalmente, vale aludir dos acápites del Art. 312:

Las organizaciones políticas tienen por funciones de obligatorio cumplimiento, las siguientes:

1. Representar a las diferentes posiciones e intereses que se expresan en la sociedad.

2. Seleccionar y nominar candidatos para puestos electivos.

Así, pese a carecer de términos relativos a la democracia comunitaria o de inclusión de la diversidad cultural, los tres artículos citados dan la posibilidad de desarrollar una normativa derivada de organizaciones 
políticas para que los introduzcan, así como para determinar una reglamentación de cuotas de las listas de candidaturas que bien podría ser a partir de la proporción de población indígena, afroecuatoriana y montubia del país en las organizaciones de carácter nacional y en las organizaciones de carácter local, para que existan participantes de las distintas nacionalidades y pueblos que habitan en el respectivo territorio.

Es fundamental revisar los mecanismos existentes para "asegurar que las votaciones y los escrutinios traduzcan la expresión auténtica, libre, democrática y espontánea de la ciudadanía y sean el reflejo oportuno de la voluntad del electorado expresada en las urnas" (Código de la Democracia, 2009, Art. 6), que se pronuncie la voluntad soberana del pueblo, "cuya voluntad es el fundamento de la autoridad [por medio del voto]" (Constitución de 2008, Art. 1; Código de la Democracia, 2009, Art. 1 y 10) y se representen las diferentes posiciones e intereses que se manifiestan en la sociedad, seleccionando y nominando a candidatos para estos puestos electivos (cfr. Código de la Democracia, 2009, Art. 312).

El análisis que exponemos a continuación de los casos seleccionados da buenas pautas con respecto a esta perspectiva, que está por construirse a través de herramientas electorales. 


\section{Análisis de casos}

En este acápite presentamos el estudio de los resultados electorales en los cinco cantones seleccionados con los criterios ya descritos; esto es, considerando al menos uno por cada pueblo (indígena, afroecuatoriano y montubio). En el caso indígena, que cuenta con catorce nacionalidades y diecinueve pueblos al presente, según el CODENPE, se presentan tres casos de contraste (uno de población autodefinida kichwa de la Sierra; uno de kichwa de la Amazonía y uno de población shuar). Cada uno de ellos cuenta con más de dos tercios de la población que se autodefine como perteneciente a uno de estos pueblos.

Si bien el análisis es fácilmente aplicable para los datos de asambleístas (tanto nacionales como provinciales), ya que hubo candidatos pertenecientes a los pueblos indígenas, afroecuatorianos y montubios, se estimó relevante la exploración de los datos del sufragio orientados a la Presidencia de la República. Para este análisis se tomó al binomio Alberto Acosta-Marcia Caicedo, del MUPP, como representante de la agenda de pueblos y nacionalidades, pese a su alianza con el MPD, más aún, tratándose de que el binomio tiene una representante del pueblo afroecuatoriano y que Acosta, aunque no pertenece a ningún pueblo o nacionalidad de la diversidad cultural, ha estado ligado al movimiento indígena durante toda la etapa posterior al retorno de la democracia. Por otra parte, no hubo ninguna otra candidatura de representantes de pueblos y nacionalidades. A pesar de ello, en uno de los cantones analizados en la Amazonía se va a dar un particular fenómeno que puede ser también explicado como de lealtad, más que étnica, enlazada a un sentido local. 


\section{Cantón San Lorenzo (Esmeraldas)}

Este cantón esmeraldeño, situado casi en la frontera con Colombia, se divide en trece parroquias: 5 de Junio, Alto Tambo, Ancón (Pichangal), Calderón, Carondelet, Concepción, Mataje, San Javier de Cachaví, San Lorenzo, Santa Rita, Tambillo, Tululbí y Urbina.

Cuadro 1.

Datos de población Censo 2010 de San Lorenzo (Esmeraldas)

\section{Cantón San Lorenzo (Esmeraldas)}

Número de habitantes: 42486

Porcentaje de población que se autoidentifica como afrodescendiente: $72,16 \%$

Fuente: INEC (2010)

\section{Resultados electorales}

Los resultados electorales para la Presidencia de la República (Ver Tabla 1) otorgan su apoyo de forma mayoritaria al candidato Rafael Correa del Movimiento Patria Altiva i Soberana (PAIS), con un 64\% de los votos válidos. En segundo lugar queda el binomio Lasso-Solines de CREO, con un alejado 15\%. La candidatura de MUPP-MPD conformada por Alberto Acosta junto a Marcia Caicedo, la única postulante de origen afrodescendiente, logró un $10 \%$ de los votos, permaneciendo en tercera posición en el escrutinio. 
Tabla 1.

Resultados electorales 2013 para la Presidencia de la República en San Lorenzo (Esmeraldas)

\begin{tabular}{l|c|c|c|c|c|c|c|c|c}
\hline \multicolumn{1}{|c|}{ Cantón } & $\begin{array}{c}\text { Lucio } \\
\text { Gutié- } \\
\text { rrez }\end{array}$ & $\begin{array}{c}\text { Álvaro } \\
\text { Noboa }\end{array}$ & $\begin{array}{c}\text { Nelson } \\
\text { Zavala }\end{array}$ & $\begin{array}{c}\text { Alberto } \\
\text { Acosta }\end{array}$ & $\begin{array}{c}\text { Gui- } \\
\text { llermo } \\
\text { Lasso }\end{array}$ & $\begin{array}{c}\text { Mau- } \\
\text { ricio } \\
\text { Rodas }\end{array}$ & $\begin{array}{c}\text { Nor- } \\
\text { man } \\
\text { Wray }\end{array}$ & $\begin{array}{c}\text { Rafael } \\
\text { Correa }\end{array}$ & $\begin{array}{c}\text { Votos } \\
\text { válidos }\end{array}$ \\
\hline $\begin{array}{l}\text { San } \\
\text { Lorenzo }\end{array}$ & 297 & 371 & 684 & 1420 & 2186 & 148 & 127 & 9493 & 14726 \\
\hline$\%$ & 2 & 3 & 4 & 10 & 15 & 1 & 1 & 64 & 100 \\
\hline
\end{tabular}

Fuente: CNE (2013). Elaboración propia

Con respecto a los asambleístas nacionales (Ver Tabla 2), se observa que resulta también ganador PAIS con un 58\%, seguida del PRE con un $13 \%$, y a continuación el MUPP-MPD con un $8 \%$.

Tabla 2.

Resultados electorales 2013 de Asambleístas nacionales en San Lorenzo

\begin{tabular}{l|c|c|c|c|c|c|c|c|c|c|c|c}
\hline \multicolumn{10}{c}{ Asambleístas nacionales } \\
\hline \multicolumn{1}{c|}{ Cantón } & AVANZA & CREO & PAIS & $\begin{array}{c}\text { MUPP- } \\
\text { MPD }\end{array}$ & PRE & PRIAN & PSC & PS-FA & PSP & RUPTURA & SUMA & $\begin{array}{c}\text { Votos } \\
\text { válidos }\end{array}$ \\
\hline $\begin{array}{l}\text { San } \\
\text { Lorenzo }\end{array}$ & 2127 & 9588 & 71263 & 11948 & 15705 & 2753 & 1824 & 1473 & 2507 & 1385 & 1600 & 122173 \\
\hline$\%$ & 2 & 8 & 58 & 10 & 13 & 2 & 1 & 1 & 2 & 1 & 1 & 100 \\
\hline
\end{tabular}

Fuente: CNE (2013). Elaboración propia

Individualmente, los candidatos para asambleístas nacionales más votados fueron, en su orden, Gabriela Rivadeneira, Iván Hurtado y Fernando Cordero. Como se puede apreciar (Ver Tabla 3), se produjo una significativa adhesión unipersonal al candidato Hurtado por parte de los sufragantes de San Lorenzo ya que, pese a ser el octavo en la lista, fue el segundo con más respaldo en el cantón. Iván Hurtado, afrodescendiente de la provincia de Esmeraldas, podría promover una doble 
identificación en el electorado que conllevaría esta lealtad, si bien también se plantea la hipótesis que explicaría esta fidelidad ligada a ser una figura histórica del fútbol ecuatoriano, lo cual, desde nuestra perspectiva, definitivamente es influyente. Este ejemplo de lealtad a un candidato resulta emblemático y comparable únicamente con el caso de Diana Atamaint, de nacionalidad indígena shuar en el cantón Taisha, como se expondrá en la siguientes líneas. De cualquier modo, se puede afirmar que la triple condición de Hurtado detonó una gran adhesión en San Lorenzo, la mayor, en términos unipersonales, de los ejemplos aquí estudiados.

Tabla 3.

Asambleístas nacionales más votados en San Lorenzo, 2013

\begin{tabular}{c|c|c}
\hline Asambleístas nacionales & Partido & Votos válidos \\
\hline Gabriela Rivadeneira & PAIS & 5924 \\
\hline Iván Hurtado & PAIS & 5106 \\
\hline Fernando Cordero & PAIS & 4924 \\
\hline
\end{tabular}

Fuente: CNE (2013). Elaboración propia

Tabla 4.

Asambleístas nacionales electos, 2013

\begin{tabular}{c|c}
\hline Asambleístas nacionales & Partido \\
\hline Mae Montaño Valencia & CREO \\
\hline Patricio Donoso & CREO \\
\hline Carlos Viteri Gualinga & PAIS \\
\hline Fernando Cordero Cueva & PAIS \\
\hline Gabriela Rivadeneira & PAIS \\
\hline Iván Hurtado Angulo & PAIS \\
\hline Linda Machuca & PAIS \\
\hline
\end{tabular}




\begin{tabular}{c|c}
\hline Marcela Aguiñaga V. & PAIS \\
\hline Marllely Vásconez Arteaga & PAIS \\
\hline Miguel Carvajal Aguirre & PAIS \\
\hline Lourdes Tibán & MUPP-MPD \\
\hline Abdalá Bucaram & PRE \\
\hline Cynthia Viteri & PSC \\
\hline Gilmar Gutiérrez & PSP \\
\hline Ramiro Aguilar Torres & SUMA \\
\hline
\end{tabular}

Fuente: CNE (2013). Elaboración propia

Finalmente se observa (Ver Tablas 5, 6 y 7) que, con respecto a los resultados para asambleístas provinciales, con relación a los partidos gana PAIS con un 56\%, seguido por el PRE con un 11\%, y en tercer lugar CREO con $7 \%$. Esto es sumamente interesante, en vista de que PAIS vence claramente, pese a no tener ningún candidato afrodescendiente; de hecho llama también la atención que CREO tampoco dispone de aspirantes del pueblo afroecuatoriano y queda tercero; el PRE sí cuenta con dos candidatos afrodescendientes. De este modo se observa que en San Lorenzo, cantón con un 72,16\% de personas que se autoidentifican como afroecuatorianos, en las candidaturas para asambleístas provinciales, que en teoría connotan una mayor identidad local, ganan candidatos no afrodescendientes. Esto no deja de ser resaltable ya que demostraría una mayor fidelidad hacia un partido político, en esta ocasión PAIS, que hacia representantes afroecuatorianos. Nuevamente aparece la pregunta de Iván Hurtado, relativa a si fue más una identidad de pueblo o vinculada al futbol, que genera también adhesiones incorruptibles. Y Hurtado tiene a su favor, además, haber ostentado durante varios años el cargo de capitán inamovible de la selección nacional. Esmeraldas, asimismo, ha sido desde siempre una provincia que se ha caracterizado por ser cuna de históricos futbolistas y deportistas de dis- 
tintas disciplinas. Cabe pues, investigar las relaciones de identidad hacia el deporte, que bien pudieran competir con la identidad de pueblo o ser complementarias en el caso de esta provincia. No hay que perder de vista tampoco que Jaime Hurtado, el histórico líder del MPD, afroecuatoriano de la provincia de Esmeraldas, comenzó brillando como basquetbolista de élite.

\section{Tabla 5.}

Resultados electorales 2013 de asambleístas provinciales en San Lorenzo, 2013

\begin{tabular}{|c|c|c|c|c|c|c|c|c|c|c|c|c|c|}
\hline \multicolumn{14}{|c|}{ Asambleístas provinciales } \\
\hline Cantón & AVANZA & CREO & PAIS & $\begin{array}{l}\text { MUPP- } \\
\text { MPD }\end{array}$ & PRE & PRIAN & PSC & PS-FA & PSP & PUEBLO & RUPTURA & SUMA & $\begin{array}{c}\text { Votos } \\
\text { Válidos }\end{array}$ \\
\hline $\begin{array}{l}\text { San } \\
\text { Lorenzo }\end{array}$ & 1670 & 2558 & 19678 & 3436 & 3893 & 740 & 454 & 658 & 782 & 554 & 282 & 596 & 35301 \\
\hline$\%$ & 2 & 8 & 58 & 10 & 13 & 2 & 1 & 1 & 2 & 2 & 1 & 1 & 100 \\
\hline
\end{tabular}

Fuente: CNE (2013). Elaboración propia

Tabla 6.

Asambleístas provinciales más votados en San Lorenzo, 2013

\begin{tabular}{c|c|c}
\hline Asambleístas provinciales & Partido & Votos válidos \\
\hline Lenin Lara & PAIS & 6413 \\
\hline Esperanza Galván & PAIS & 4544 \\
\hline Gabriel Rivera & PAIS & 4437 \\
\hline
\end{tabular}

Fuente: CNE (2013). Elaboración propia 
Tabla 7.

Asambleístas provinciales electos por la

provincia de Esmeraldas, 2013

\begin{tabular}{c|c}
\hline Asambleístas provinciales & Partido \\
\hline Ramiro Tenelema & CREO \\
\hline Esperanza Galván Gracia & PAIS \\
\hline Gabriel Rivera & PAIS \\
\hline Lenin Lara Rivadeneira & PAIS \\
\hline
\end{tabular}

Fuente: CNE (2013). Elaboración propia 


\section{Cantón Salitre (Guayas)}

El cantón Salitre formó parte de la circunscripción número cuatro ${ }^{13}$ de la provincia de Guayas en las elecciones 2013, y es citado comúnmente como la capital montubia del Ecuador. Reportado en el Censo 2010 todavía como cantón Urbina Jado, los datos de población de esta fuente contemplan a cuatro de sus parroquias, siendo estas las que han sido tomadas como referencia para el análisis de los datos electorales: El Salitre (Las Ramas), General Vernaza, Junquillal, La Victoria (Nauza).

Cuadro 2.

Datos de población Censo 2010 de Salitre (Guayas)

Cantón Salitre (Guayas)

Número de habitantes: 57402

Porcentaje de población que se autoidentifica como montubia: 79,53\%

Fuente: INEC (2010)

\section{Resultados electorales}

En la elección a la Presidencia, en el cantón Salitre (Ver Tabla 8), el binomio Correa-Glas alcanzó la mayoría, con un $69 \%$ de los votos válidos. En el segundo lugar se dio prácticamente un empate técnico entre el binomio de CREO Lasso-Solines, y Gutiérrez-Boyes de Sociedad Patriótica (PSP), con el $11 \%$. En este caso, si bien no se puede colegir que haya una lealtad hacia una candidatura de pueblos o nacionalida-

13 La circunscripción número cuatro incluye los cantones de la provincia del Guayas que no están dentro de los distritos 1, 2 y 3, entre los que se encuentra la zona electoral número 18, denominada también Salitre (CNE, 2013). La zona electoral contempla un total de ocho parroquias que, sin embargo, no computaron en el Censo 2010 dentro del cantón "Urbina Jado". Para el análisis de datos solo se han tomado en cuenta los resultados para las cuatro parroquias descritas en dicho Censo y no la totalidad que forma la zona electoral número 18 . 
des, ya que ni Rafael Correa ni Jorge Glas se han autodefinido como montubios, es posible subrayar la afinidad regional y provincial, puesto que ambos son precisamente de la misma provincia en la que se ubica Salitre, Guayas. Adicionalmente cabe anotar que muchas organizaciones montubias hicieron manifestaciones públicas en eventos, mítines o medios de comunicación, adhiriéndose y pidiendo el voto masivamente a todas las candidaturas de PAIS (CRE satelital, del 6 de febrero de 2013).

Tabla 8.

Resultados electorales 2013 para la Presidencia de la República en Salitre (Guayas)

\begin{tabular}{l|c|c|c|c|c|c|c|c|c}
\hline \multicolumn{1}{c}{ Presidente } \\
\hline Cantón & $\begin{array}{c}\text { Lucio } \\
\text { Gutié- } \\
\text { rrez }\end{array}$ & $\begin{array}{c}\text { Álvaro } \\
\text { Noboa }\end{array}$ & $\begin{array}{c}\text { Nelson } \\
\text { Zavala }\end{array}$ & $\begin{array}{c}\text { Alberto } \\
\text { Acosta }\end{array}$ & $\begin{array}{c}\text { Gui- } \\
\text { llermo } \\
\text { Lasso }\end{array}$ & $\begin{array}{c}\text { Mau- } \\
\text { ricio } \\
\text { Rodas }\end{array}$ & $\begin{array}{c}\text { Nor- } \\
\text { man } \\
\text { Wray }\end{array}$ & $\begin{array}{c}\text { Rafael } \\
\text { Correa }\end{array}$ & $\begin{array}{c}\text { Votos } \\
\text { válidos }\end{array}$ \\
\hline Salitre & 3701 & 1206 & 867 & 275 & 3720 & 556 & 139 & 22948 & 33412 \\
\hline$\%$ & 11 & 4 & 3 & 1 & 11 & 2 & 0 & 69 & 100 \\
\hline
\end{tabular}

Fuente CNE (2013). Elaboración propia

De la misma manera, los resultados electorales para asambleístas nacionales (Ver Tablas 9 y 10) reflejan la victoria de PAIS, con un 62\% de los votos válidos, seguido lejanamente por el PSP y por el PRE, ambos con cifras del $9 \%$. Si bien la tendencia se confirma contundentemente, sorprende el segundo puesto del PSP pues no cuenta con candidatos que se identifiquen como montubios en su lista, al tiempo que, de manera habitual, ha sido identificada con la Amazonía. Así, los candidatos más votados para asambleístas nacionales son Gabriela Rivadeneira, Marcela Aguińaga y Fernando Cordero, todos de PAIS. Al ocupar Aguiñaga la tercera en la lista de postulantes, los datos revelan más adhesiones unipersonales a esta candidata que a Fernando Cordero, lo cual sí demuestra nuevamente afinidad al voto por interlocutores de la 
misma provincia: Guayas; en este caso podría también decirse que hay, de forma indirecta, fidelidad hacia un candidato montubio ya que el candidato alterno de Marcela Aguiñaga era Jorge Loor Cevallos, quien se autoidentifica como tal. No obstante, al no aparecer en la papeleta y ser Aguińaga una mujer guayasense, que además ha tenido un alto perfil por haber sido Ministra del Presidente Rafael Correa, esto no pasa de ser una conjetura, la cual habría que comprobar específicamente. De cualquier modo, lo que sí es factible confirmar es la deferencia hacia los candidatos de PAIS y, más particularmente, a aquellos de Guayas.

\section{Tabla 9.}

Resultados electorales 2013 de asambleístas nacionales en Salitre

\begin{tabular}{c|c|c|c|c|c|c|c|c|c|c|c|c}
\hline \multicolumn{10}{c}{ Asambleístas nacionales } \\
\hline Cantón & AVANZA & CREO & PAIS & $\begin{array}{c}\text { MUPP } \\
\text { MPD }\end{array}$ & PRE & PRIAN & PSC & PS-FA & PSP & RUPTURA & SUMA & $\begin{array}{c}\text { Votos } \\
\text { válidos }\end{array}$ \\
\hline Salitre & 7023 & 13232 & 160843 & 4178 & 22608 & 9107 & 1162 & 12232 & 23005 & 2501 & 4242 & 259683 \\
\hline$\%$ & 3 & 5 & 62 & 2 & 9 & 4 & 0 & 5 & 9 & 1 & 2 & 100 \\
\hline
\end{tabular}

Fuente: CNE (2013). Elaboración propia

Tabla 10.

Asambleístas nacionales más votados en Salitre, 2013

\begin{tabular}{c|c|c}
\hline Asambleístas nacionales & Partido & Votos válidos \\
\hline Gabriela Rivadeneira & PAIS & 12856 \\
\hline Marcela Aguiñaga & PAIS & 11107 \\
\hline Fernando Cordero & PAIS & 11146 \\
\hline
\end{tabular}

Fuente: CNE (2013). Elaboración propia 
Respecto de los asambleístas provinciales (Ver Tablas 11, 12 y 13) el mayor respaldo se orienta hacia PAIS, con un $62 \%$, seguido remotamente por el PSP, con un 9\% y el PRE, con un 7\%. Como observamos, esta tendencia es semejante a la hallada en los resultados de asambleístas nacionales. Los candidatos más votados fueron, en su orden, Denisse Robles, Gastón Gagliardo, Verónica Guevara, Ángel Rivero y Luiba Cuesta; esto coincide perfectamente con la disposición de la lista 35, lo cual comprueba que hubo aquí inclinación al voto por todos los candidatos de una sola lista. Sin embargo, en otros sectores de la circunscripción 4 del Guayas recibió más votos Cuesta, por lo que ella finalmente llega a ser la cuarta Asambleísta electa, pese a figurar quinta en la papeleta. Es importante anotar que esto demuestra y confirma la identidad y el apoyo a PAIS, inclusive a pesar que en otras listas, como la presentada por SUMA, se postularon candidatos que se autoidentifican como montubios (Lizett Moreira y Jaime Macías). Sin embargo, según la organización Pueblo Montubio del Ecuador, "ninguno de los postulantes a la Asamblea Nacional inscritos por el Distrito 4 del Guayas, en Los Ríos y Manabí, tiene raíces del colectivo" (El Telégrafo, 2 de diciembre de 2012). Ello, si bien no determina lealtad o deslealtad, más aún tratándose de una polémica y un conflicto en las organizaciones con respecto a la pertenencia de ciertos representantes del pueblo montubio, no deja de ser una información valiosa para avanzar en la comprensión de las dinámicas electorales.

\section{Tabla 11.}

Resultados electorales 2013 de asambleístas provinciales en Salitre

\begin{tabular}{c|c|c|c|c|c|c|c|c|c|c|c}
\hline \multicolumn{10}{c}{ Asambleístas provinciales } \\
\hline Cantón & AVANZA & $\begin{array}{c}\text { PSC- } \\
\text { MDG }\end{array}$ & PAIS & $\begin{array}{c}\text { MUPP/ } \\
\text { MPD }\end{array}$ & PRE & PRIAN & PS-FA & PSP & RUPTURA & SUMA & $\begin{array}{c}\text { Votos } \\
\text { válidos }\end{array}$ \\
\hline Salitre & 4826 & 5980 & 55638 & 1617 & 6141 & 3496 & 606 & 8501 & 792 & 2284 & 89791 \\
\hline$\%$ & 5 & 7 & 62 & 2 & 7 & 4 & 1 & 9 & 1 & 3 & 100 \\
\hline
\end{tabular}

Fuente: CNE (2013). Elaboración propia 
Tabla 12.

Asambleístas provinciales más votados en Salitre, 2013

\begin{tabular}{c|c|c}
\hline Asambleístas provinciales & Partido & Votos válidos \\
\hline Denisse Robles & PAIS & 13631 \\
\hline Gastón Gagliardo & PAIS & 10917 \\
\hline Verónica Guevara & PAIS & 10710 \\
\hline Ángel Rivero & PAIS & 10440 \\
\hline
\end{tabular}

Fuente: CNE (2013). Elaboración propia

Tabla 13.

Asambleístas provinciales electos por la circunscripción 4 de Guayas, 2013

\begin{tabular}{c|c}
\hline Asambleístas provinciales & Partido \\
\hline Denisse Robles Andrade & PAIS \\
\hline Gastón Gagliardo Loor & PAIS \\
\hline Liuba Cuesta Ríos & PAIS \\
\hline Verónica Guevara Villacrés & PAIS \\
\hline
\end{tabular}

Fuente: CNE (2013). Elaboración propia 


\section{Cantón Guamote (Chimborazo)}

Guamote, en la Sierra centro del Ecuador, se encuentra dividido en tres parroquias: Cebadas, Guamote y Palmira.

\section{Cuadro 3.}

Datos de población Censo 2010 de Guamote (Chimborazo)

\section{Cantón Guamote (Chimborazo)}

Número de habitantes: 42664

Porcentaje de población que se autoidentifica como indígena: $94,49 \%$

Nacionalidades: Puruhá (76,57\%), Kichwa de la Sierra (20,38\%)

Fuente: INEC (2010)

\section{Resultados electorales}

En el cantón Guamote, en las elecciones presidenciales (Ver Tabla 14), gana el binomio Correa-Glas, de PAIS, con un porcentaje del 48\%. En segundo lugar queda el binomio de CREO, Lasso-Solines, con un $16 \% \mathrm{y}$, en tercera posición, el binomio Gutiérrez-Boyes, del PSP. El binomio Acosta-Caicedo, del MUPP-MPD, llega solo al quinto puesto, con el $10 \%$ de votos. Evidentemente hay una supremacía de PAIS y una debilidad de la propuesta que se podría identificar con el pueblo indígena, la del MPD y el MUPP. Este dato llama la atención, en vista de que MUPP tuvo en el pasado mucha fuerza en Guamote; de hecho, el Prefecto provincial de Chimborazo y ex Alcalde de Guamote, de autoidentificación indígena, Mariano Curicama, proviene de esta fuerza política. 
Tabla 14.

Resultados electorales 2013 para la Presidencia de la República en Guamote (Chimborazo)

\begin{tabular}{c|c|c|c|c|c|c|c|c|c}
\hline \multicolumn{1}{c}{ Presidente } \\
\hline Cantón & $\begin{array}{c}\text { Lucio } \\
\text { Gutié- } \\
\text { rrez }\end{array}$ & $\begin{array}{c}\text { Álvaro } \\
\text { Noboa }\end{array}$ & $\begin{array}{c}\text { Nelson } \\
\text { Zavala }\end{array}$ & $\begin{array}{c}\text { Alberto } \\
\text { Acosta }\end{array}$ & $\begin{array}{c}\text { Gui- } \\
\text { llermo } \\
\text { Lasso }\end{array}$ & $\begin{array}{c}\text { Mau- } \\
\text { ricio } \\
\text { Rodas }\end{array}$ & $\begin{array}{c}\text { Nor- } \\
\text { man } \\
\text { Wray }\end{array}$ & $\begin{array}{c}\text { Rafael } \\
\text { Correa }\end{array}$ & $\begin{array}{c}\text { Votos } \\
\text { válidos }\end{array}$ \\
\hline Guamote & 3312 & 1008 & 375 & 2194 & 3617 & 872 & 257 & 10436 & 21891 \\
\hline$\%$ & 2 & 3 & 4 & 10 & 15 & 1 & 1 & 64 & 100 \\
\hline
\end{tabular}

Fuente: CNE (2013). Elaboración propia

Dicho resultado, si bien se ratifica en la votación para asambleístas nacionales (Ver Tablas 15 y 16), también contiene un matiz a resaltar que podría relacionarse con la lealtad hacia un candidato indígena. Y es que así como en este cantón PAIS aventaja con un $42 \%$ y los más votados para asambleístas nacionales son precisamente los postulantes de este movimiento, que resultan efectivamente elegidos, destaca, no obstante, que el indígena kichwa amazónico Carlos Viteri Gualinga -también de este partido-, que en la papeleta ocupaba el sexto puesto, en Guamote quedó en el quinto lugar entre los más votados. De este modo, por un lado se revela que en este cantón la población sufragó por todos los candidatos de una sola lista para elegir a los asambleístas nacionales y con una preferencia hacia PAIS y, por otro lado, que un porcentaje de sufragantes, aún exiguo, votó personalizadamente y con distinción a Carlos Viteri; de ahí que este obtenga una posición más favorable que la candidata Marllely Vásconez, la quinta en la lista de PAIS, por una pequeńa diferencia en el sufragio.

Esta posible afinidad con un candidato indígena contrasta con los resultados obtenidos por MUPP-MPD. Recordemos que en su propuesta aparecían dos candidatas indígenas: Lourdes Tibán, kichwa de Cotopaxi y Diana Atamaint, shuar de la Amazonía, que no figuran entre las más votadas. Esto nuevamente revela una lealtad en primera instancia hacia el movimiento PAIS, en congruencia con lo ocurrido para el binomio presidencial. 
Tabla 15.

Resultados electorales 2013 de asambleístas nacionales en Guamote

\begin{tabular}{c|c|c|c|c|c|c|c|c|c|c|c|c}
\hline \multicolumn{10}{c}{ Asambleístas nacionales } \\
\hline Cantón & AVANZA & CREO & PAIS & $\begin{array}{c}\text { MUPP- } \\
\text { MPD }\end{array}$ & PRE & PRIAN & PSC & PS-FA & PSP & RUPTURA & SUMA & $\begin{array}{c}\text { Votos } \\
\text { válidos }\end{array}$ \\
\hline Guamote & 5156 & 13473 & 61311 & 20855 & 4101 & 6560 & 2600 & 2257 & 18731 & 3385 & 6913 & 145072 \\
\hline$\%$ & 4 & 9 & 42 & 14 & 3 & 5 & 2 & 5 & 13 & 2 & 5 & 100 \\
\hline
\end{tabular}

Fuente: CNE (2013). Elaboración propia

Tabla 16.

Asambleístas nacionales más votados en Guamote, 2013

\begin{tabular}{c|c|c}
\hline Asambleístas nacionales & Partido & Votos válidos \\
\hline Gabriela Rivadeneira & PAIS & 5248 \\
\hline Fernando Cordero & PAIS & 4621 \\
\hline Marcela Aguiñaga & PAIS & 4336 \\
\hline Miguel Carvajal & PAIS & 4087 \\
\hline Carlos Viteri & PAIS & 4021 \\
\hline Marllely Vásconez & PAIS & 4005 \\
\hline
\end{tabular}

Fuente: CNE (2013). Elaboración propia

Asimismo, los resultados para asambleístas provinciales (Ver Tablas 17, 18 y 19) dan como ganador a PAIS, en esta ocasión en alianza con el MUPP, obteniendo un 38\%. Le sigue de cerca Amanta Yuyai (MAY), movimiento político indígena vinculado a la religión evangélica, con un $21 \%$. Los candidatos más votados son los pertenecientes a PAIS, Mauro Andino y Rosa Elvira Muñoz, esta última indígena kichwa. Pedro Curichumbi, también indígena kichwa de MAY, es el tercero más votado del cantón. Así, se expresa de nuevo una lealtad de voto indígena manifiesta más específicamente en el caso de Curichumbi, ya que 
Muñoz efectivamente estaba segunda en la lista de PAIS; sin embargo, Curichumbi no llegó a ser Asambleísta.

\section{Tabla 17.}

Resultados electorales 2013 de asambleístas provinciales en Guamote

\begin{tabular}{c|c|c|c|c|c|c|c|c|c|c|c|c}
\hline \multicolumn{10}{c}{ Asambleístas provinciales } \\
\hline Cantón & MAY & AVANZA & CREO & $\begin{array}{c}\text { PAIS- } \\
\text { MUPP }\end{array}$ & MPD & PRIAN & PSC & PS-FA & PSP & RUPTURA & SUMA & $\begin{array}{c}\text { Votos } \\
\text { válidos }\end{array}$ \\
\hline Guamote & 10950 & 2477 & 3415 & 19961 & 3830 & 2612 & 522 & 695 & 4350 & 783 & 2673 & 52268 \\
\hline$\%$ & 21 & 5 & 7 & 38 & 7 & 5 & 1 & 1 & 8 & 1 & 5 & 100 \\
\hline
\end{tabular}

Fuente: CNE (2013). Elaboración propia

Tabla 18.

Asambleístas provinciales más votados en Guamote, 2013

\begin{tabular}{c|c|c}
\hline Asambleístas provinciales & Partido & Votos válidos \\
\hline Mauro Andino & PAIS & 13631 \\
\hline Rosa Elvira Muńoz & PAIS & 10917 \\
\hline Pedro Curichumbi & MAY & 10710 \\
\hline
\end{tabular}

Fuente: CNE (2013). Elaboración propia

Tabla 19.

Asambleístas electos por la provincia de Chimborazo, 2013

\begin{tabular}{c|c}
\hline Asambleístas provinciales & Partido \\
\hline José Ricardo Moncayo & CREO \\
\hline Mauro Andino Reinoso & PAIS-MUPP \\
\hline Rosa Elvira Muñoz & PAIS-MUPP \\
\hline Paco Fierro & PSP \\
\hline
\end{tabular}

Fuente: CNE (2013). Elaboración propia 


\section{Cantón Taisha (Morona Santiago)}

Taisha, cantón de la Amazonía y el más oriental de la provincia de Morona Santiago, incluye en su jurisdicción cinco parroquias: Huasaga, Macuma, Pumpuentsa, Taisha y Tuutinentza. De reciente cantonización (1996), el acceso a su territorio se realiza fundamentalmente a través de un servicio aéreo o a pie.

\section{Cuadro 4.}

Datos de población Censo 2010 de Taisha (Morona Santiago)

Cantón Taisha (Morona Santiago)

Número de habitantes: 18437

Porcentaje de población que se autoidentifica como indígena: $95.85 \%$

Nacionalidades: Shuar (73,1\%), Achuar (20,38\%)

Fuente: INEC (2010)

\section{Resultados electorales}

El sufragio en el cantón Taisha, en Morona Santiago, exhibe una clara fidelidad a los pueblos y nacionalidades, con los matices oportunos. Así, el cantón Taisha (Ver Tabla 20) votó mayoritariamente para la Presidencia por el binomio Acosta-Caicedo, del MUPP-MPD con prácticamente tres cuartos del total de votos, un $74 \%$. En segundo lugar, con solo un $11 \%$, quedó el binomio Gutiérrez-Boyes, del PSP, que desde hace más de diez años había triunfado en casi toda la Amazonía. Solo en tercer lugar llega el binomio ganador a escala nacional de PAIS, Correa-Glas, con un 7\% del total de los votos válidos; es decir menos de un décimo de votos del binomio aquí vencedor. 
Tabla 20.

Resultados electorales 2013 para la Presidencia de la República en Taisha (Morona Santiago)

\begin{tabular}{l|c|c|c|c|c|c|c|c|c}
\hline \multicolumn{1}{c|}{ Presidente } \\
\hline Cantón & $\begin{array}{c}\text { Lucio } \\
\text { Gutié- } \\
\text { rrez }\end{array}$ & $\begin{array}{c}\text { Álvaro } \\
\text { Noboa }\end{array}$ & $\begin{array}{c}\text { Nelson } \\
\text { Zavala }\end{array}$ & $\begin{array}{c}\text { Alberto } \\
\text { Acosta }\end{array}$ & $\begin{array}{c}\text { Gui- } \\
\text { llermo } \\
\text { Lasso }\end{array}$ & $\begin{array}{c}\text { Mau- } \\
\text { ricio } \\
\text { Rodas }\end{array}$ & $\begin{array}{c}\text { Nor- } \\
\text { man } \\
\text { Wray }\end{array}$ & $\begin{array}{c}\text { Rafael } \\
\text { Correa }\end{array}$ & $\begin{array}{c}\text { Votos } \\
\text { válidos }\end{array}$ \\
\hline Taisha & 650 & 22 & 77 & 4390 & 312 & 21 & 21 & 434 & 5927 \\
\hline$\%$ & 11 & 0 & 1 & 74 & 5 & 0 & 0 & 7 & 100 \\
\hline
\end{tabular}

Fuente: CNE (2013). Elaboración propia

El escrutinio para asambleístas nacionales (Ver Tablas 21 y 22) otorga un apoyo incluso mayor a la alianza MUPP-MPD, de casi el 80\% de los votos. Al revisar estas cifras por candidato, la Asambleísta más votada es Lourdes Tibán indígena kichwa, seguida de Diana Atamaint, indígena shuar quien, a pesar de ocupar la quinta posición en la lista MUPP-MPD, es la segunda con más respaldo en el cantón Taisha. Ello responde al voto personalizado, con preferencia hacia Atamaint. Este resultado muestra la lealtad de Taisha a las candidaturas que se identifican con su pueblo, en este caso particular hacia la candidata de su misma nacionalidad shuar.

Tabla 21.

Resultados electorales 2013 de asambleístas nacionales en Taisha

\begin{tabular}{c|c|c|c|c|c|c|c|c|c|c|c|c}
\hline \multicolumn{10}{c}{ Asambleístas nacionales } \\
\hline Cantón & AVANZA & CREO & PAIS & $\begin{array}{c}\text { MUPP- } \\
\text { MPD }\end{array}$ & PRE & PRIAN & PSC & PS-FA & PSP & RUPTURA & SUMA & $\begin{array}{c}\text { Votos } \\
\text { válidos }\end{array}$ \\
\hline Taisha & 365 & 1428 & 3113 & 37657 & 346 & 325 & 270 & 379 & 3091 & 212 & 344 & 47530 \\
\hline$\%$ & 1 & 3 & 7 & 79 & 1 & 1 & 1 & 1 & 7 & 0 & 1 & 100 \\
\hline
\end{tabular}

Fuente: CNE (2013). Elaboración propia 
Tabla 22.

Asambleístas nacionales más votados en Taisha, 2013

\begin{tabular}{c|c|c}
\hline Asambleístas nacionales & Partido & Votos válidos \\
\hline Lourdes Tibán & MUPP-MPD & 3467 \\
\hline Diana Atamaint & MUPP-MPD & 2894 \\
\hline Jorge Escala & MUPP-MPD & 2628 \\
\hline
\end{tabular}

Fuente: CNE (2013). Elaboración propia

Finalmente, los resultados para asambleístas provinciales (Ver Tablas 23, 24 y 25) respaldan la candidatura de MUPP-MPD, con un porcentaje superior al de los resultados presidenciales y de asambleístas nacionales, el 83\% de los votos válidos. En este caso, el candidato a la cabeza es el indígena shuar Pepe Acacho, seguido de Yolanda Antun Tsamaraint, también shuar, y Vethowen Chica. El escrutinio final de la provincia de Morona Santiago dejó sin la segunda curul a la alianza MUPP-MPD (Ver Tabla 25), siendo Chica representante de PAIS, el que llega a formar parte de la Asamblea Nacional a pesar de que en este cantón quedó tercero, con un bajo porcentaje del 3,6\% con respecto del total de votos del cantón.

Tabla 23.

Resultados electorales 2013 de asambleístas provinciales en Taisha

\begin{tabular}{c|c|c|c|c|c|c}
\hline \multicolumn{7}{c}{ Asambleístas provinciales } \\
\hline Cantón & CREO & PAIS & $\begin{array}{c}\text { MUPP- } \\
\text { MPD }\end{array}$ & PRIAN & PSP & Votos Válidos \\
\hline Taisha & 302 & 570 & 7627 & 75 & 509 & 9083 \\
\hline$\%$ & 3 & 6 & 84 & 1 & 6 & 100 \\
\hline
\end{tabular}

Fuente: CNE (2013). Elaboración propia 
Tabla 24.

Asambleístas provinciales más votados en Taisha, 2013

\begin{tabular}{c|c|c}
\hline Asambleístas nacionales & Partido & Votos válidos \\
\hline Pepe Luis Acacho & MUPP-MPD & 4420 \\
\hline Raquel Yolanda Antun & MUPP-MPD & 3207 \\
\hline Vethowen Chica & PAIS & 331 \\
\hline
\end{tabular}

Fuente: CNE (2013). Elaboración propia

Tabla 25.

Asambleístas electos por la provincia de Morona Santiago, 2013

\begin{tabular}{c|c}
\hline Asambleístas provinciales & Partido \\
\hline Vethowen Chica Arévalo & PAIS \\
\hline Pepe Luis Acacho & MUPP-MPD \\
\hline
\end{tabular}

Fuente: CNE (2013). Elaboración propia 


\section{Cantón Arajuno (Pastaza)}

Arajuno es otro de los cantones de la Amazonía con importante presencia de población indígena. La nacionalidad mayoritaria es la kichwa, con el apelativo habitual de la Amazonía pues poseen cualidades culturales diferentes a los kichwas de la Sierra. Arajuno está integrado por las parroquias Arajuno y Curaray. A estas parroquias se puede acceder hoy día tanto por vía aérea como terrestre desde el Puyo.

Cuadro 5.

Datos de población Censo 2010 de Arajuno (Pastaza)

Cantón Arajuno (Pastaza)

Número de habitantes: 6491

Porcentaje de población que se autoidentifica como indígena: $94,70 \%$

Nacionalidades: Kichwa (78,25\%), Huaorani (15,70\%), Shuar (2,93\%)

Fuente: INEC (2010)

\section{Resultados electorales}

En Pastaza, en el cantón Arajuno, con un 94,7 \% de personas que se autoidentifican como indígenas kichwa de la Amazonía, los resultados del sufragio con respecto a la candidatura presidencial (Ver Tabla 26) apuestan por el binomio Gutiérrez-Boyes del PSP, con un 27\% de los votos. En segundo lugar hay un empate técnico entre el binomio de PAIS, Correa-Glas y el de CREO, Lasso-Solines, ambos con un $24 \%$ (el binomio de PAIS tiene solo un voto más). En tercer puesto encontramos al binomio Acosta-Caicedo con un 22\%. Estos datos ameritan una lectura pormenorizada ante una división de votos muy reñida entre los cuatro binomios citados, ninguno de los cuales baja del 20\% de votación. A ello se añade la diferencia de respaldo entre el binomio de MUPP-MPD, que representa a la alianza de la denominada Unidad Plurinacional, frente a la vencedora PSP. Cabe mencionar que este mo- 
vimiento, en los últimos once años, ha gozado de supremacía electoral en la Amazonía, probablemente ligada a que el ex Presidente Lucio Gutiérrez, en esta elección candidato a la Presidencia, es identificado como amazónico de $\mathrm{Napo}^{14}$. Por lo tanto, para el caso de Arajuno, la posible relación de lealtad en el voto se articula con una identidad amazónica. Nótese que, además, en el binomio de la alianza MUPP-MPD, ninguno de los candidatos (Acosta mestizo; Caicedo afrodescendiente) es indígena o amazónico.

Tabla 26.

Resultados electorales 2013 para la Presidencia de la República en Arajuno (Pastaza)

\begin{tabular}{c|c|c|c|c|c|c|c|c|c}
\hline \multicolumn{10}{c}{ Presidente } \\
\hline Cantón & $\begin{array}{c}\text { Lucio } \\
\text { Gutié- } \\
\text { rrez }\end{array}$ & $\begin{array}{c}\text { Álvaro } \\
\text { Noboa }\end{array}$ & $\begin{array}{c}\text { Nelson } \\
\text { Zavala }\end{array}$ & $\begin{array}{c}\text { Alberto } \\
\text { Acosta }\end{array}$ & $\begin{array}{c}\text { Gui- } \\
\text { llermo } \\
\text { Lasso }\end{array}$ & $\begin{array}{c}\text { Mau- } \\
\text { ricio } \\
\text { Rodas }\end{array}$ & $\begin{array}{c}\text { Nor- } \\
\text { man } \\
\text { Wray }\end{array}$ & $\begin{array}{c}\text { Rafael } \\
\text { Correa }\end{array}$ & $\begin{array}{c}\text { Votos } \\
\text { válidos }\end{array}$ \\
\hline Arajuno & 819 & 18 & 17 & 668 & 753 & 40 & 13 & 754 & 3082 \\
\hline$\%$ & 27 & 1 & 1 & 22 & 24 & 1 & 0 & 24 & 100 \\
\hline
\end{tabular}

Fuente: CNE (2013). Elaboración propia

Los resultados para la Asamblea Nacional (Ver Tablas 27 y 28) cambian de partido político y respaldan la opción del MUPP-MPD y, en menor medida, la de PAIS. Ello tiene como consecuencia el apoyo a dos Asambleístas concretos, ambos vinculados a las nacionalidades indígenas: Lourdes Tibán, por el primero y Carlos Viteri, por el segundo.

Esto apunta a una notoria adhesión a candidatos indígenas. Destaca el voto, en primer lugar, a Lourdes Tibán y, en segundo lugar, a Carlos Viteri, pese a ser este indígena kichwa de la propia provincia de Pastaza. Ello podría evidenciar el ejercicio del voto por todos los candidatos de una sola lista, por encima del voto personalizado múltiple.

14 Lucio Gutiérrez es identificado con fuerza como amazónico, de la provincia del Napo, más específicamente de Tena, donde reside la mayor parte de su familia materna y paterna. No obstante, Gutiérrez nació en Quito y a tierna edad migró hacia Tena, donde hizo toda su educación primaria y secundaria. 
Tabla 27.

Resultados electorales 2013 de asambleístas nacionales en Arajuno

\begin{tabular}{c|c|c|c|c|c|c|c|c|c|c|c|c}
\hline \multicolumn{10}{c}{ Asambleístas nacionales } \\
\hline Cantón & AVANZA & CREO & PAIS & $\begin{array}{c}\text { MUPP- } \\
\text { MPD }\end{array}$ & PRE & PRIAN & PSC & PS-FA & PSP & RUPTURA & SUMA & $\begin{array}{c}\text { Votos } \\
\text { válidos }\end{array}$ \\
\hline Arajuno & 3519 & 3677 & 5424 & 5919 & 316 & 309 & 207 & 268 & 4763 & 276 & 289 & 24967 \\
\hline$\%$ & 14 & 15 & 22 & 24 & 1 & 1 & 1 & 1 & 19 & 1 & 1 & 100 \\
\hline
\end{tabular}

Fuente: CNE (2013). Elaboración propia

Tabla 28.

Asambleístas nacionales más votados en Arajuno, 2013

\begin{tabular}{c|c|c}
\hline Asambleístas nacionales & Partido & Votos válidos \\
\hline Lourdes Tibán & MUPP-MPD & 599 \\
\hline Carlos Viteri & PAIS & 479 \\
\hline Jorge Escala & MUPP-MPD & 413 \\
\hline
\end{tabular}

Fuente: CNE (2013). Elaboración propia

La elección de los asambleístas provinciales (Ver Tablas 29, 30 y 31) también se emplaza hacia la propuesta de MUPP-MPD y Avanza, con un $24 \%$ y $22 \%$ de los votos válidos, respectivamente. Ello sitúa como candidatos más votados a Marlon Santi, indígena kichwa, por MUPP-MPD y a Germán Ledesma, por Avanza. Finalmente, las curules de la Asamblea Nacional para la provincia de Pastaza fueron para este aspirante de Avanza y para Oscar Alfonso Ledesma, de PAIS. Ello obedecería a la dinámica ya referida de fidelidad a los candidatos indígenas. 
Tabla 29.

Resultados electorales 2013 de asambleístas provinciales en Arajuno

\begin{tabular}{c|c|c|c|c|c|c|c|c|c|c|c}
\hline \multicolumn{10}{c}{ Asambleístas provinciales } \\
\hline Cantón & AVANZA & CREO & PAIS & $\begin{array}{c}\text { MUPP- } \\
\text { MPD }\end{array}$ & PRE & PRIAN & PS-FA & PSP & RUPTURA & UP & $\begin{array}{c}\text { Votos } \\
\text { válidos }\end{array}$ \\
\hline Arajuno & 1093 & 874 & 638 & 1202 & 19 & 24 & 20 & 487 & 21 & 570 & 4948 \\
\hline$\%$ & 22 & 18 & 13 & 24 & 0 & 0 & 0 & 10 & 0 & 12 & 100 \\
\hline
\end{tabular}

Fuente: CNE (2013). Elaboración propia

Tabla 30.

Asambleístas provinciales más votados en Arajuno, 2013

\begin{tabular}{c|c|c}
\hline Asambleístas provinciales & Partido & Votos válidos \\
\hline Marlon Santi & MUPP-MPD & 779 \\
\hline Germán Ledesma & AVANZA & 687 \\
\hline Antonio Kubes & CREO & 545 \\
\hline
\end{tabular}

Fuente: CNE (2013). Elaboración propia

Tabla 31.

Asambleístas provinciales electos

por la provincia de Pastaza, 2013

\begin{tabular}{c|c}
\hline Asambleístas provinciales & Partido \\
\hline Germán Ledesma Zamora & AVANZA \\
\hline Óscar Ledesma Zamora & PAIS \\
\hline
\end{tabular}

Fuente: CNE (2013). Elaboración propia 


\section{Conclusiones}

Tal como se había anticipado y a partir del análisis de los artículos de la Constitución (2008), es claro que actualmente el panorama constitucional es bastante favorable para los pueblos y nacionalidades. El Estado-nación monocultural fracasó en países de enorme diversidad como el Ecuador y en la mayoría de países latinoamericanos. Por ello, la calificación del Estado como intercultural y plurinacional en el primer artículo de la Constitución vigente, es un cambio paradigmático. Y es que, como dice Amartya Sen, la libertad cultural es imprescindible para el desarrollo humano y el reto de nuestro tiempo es afrontar la diversidad cultural en lo local y lo global (cfr. Sen, 2004); una diversidad que el Ecuador históricamente ha hecho caso omiso y ha quedado invisibilizada.

A pesar de que no se hace en la Constitución una definición específica de lo que se entiende por intercultural y plurinacional, ideal para evitar malos entendidos, subvaloraciones o sobreinterpretaciones, sí se produce un reconocimiento explícito de la diversidad cultural y la búsqueda de armonizar esa diversidad en la construcción y políticas del nuevo Estado. Esto, empero, implica una nueva ingeniería institucional que cada una de las funciones del Estado debe proponerse, ya no solo como una reivindicación de las luchas de equidad étnica, sino por mandato constitucional. Pese a que en las Ciencias Sociales no hay un acuerdo respecto del concepto de interculturalidad, vale la pena aclarar que multicultural e intercultural no son lo mismo.

La categoría de multicultural da cuenta de la diversidad de culturas y su reconocimiento; sin embargo, no presume necesariamente la interacción entre pueblos y culturas sino únicamente la coexistencia. Mientras la interculturalidad prevé necesariamente la convivencia, interacción e intercambio entre las diversas culturas. De esta manera, podrían existir Estados multiculturales aunque no interculturales; no obstante, un Estado intercultural es por antonomasia un Estado multicultural (Salazar Medina, 2011: 112). 
Por otra parte, los derechos colectivos (Art. 57, 58 y 59), expresados hoy de una manera más completa que en la Constitución de 1998, resultan el paraguas conceptual y práctico más completo para trabajar las realidades, necesidades y aspiraciones de los pueblos y nacionalidades de una manera apropiada, respetuosa e integral, ya que toman en cuenta, entre otras, la posibilidad de constituir organizaciones que les representen.

De la misma manera, la participación ciudadana (Art. 95) -que además de expresar el protagonismo de la ciudadanía desde una perspectiva activa, en la discusión de los temas de interés común, la toma de decisiones y el control social, orientada por principios fundamentales que incluyen la interculturalidad- crea una forma adicional de democracia además de la representativa y directa: la democracia comunitaria. Esta, no obstante, está por definirse y ejecutarse desde una perspectiva coordinada con las formas existentes históricamente; sin embargo, es una puerta fundamental hacia el avance a una ciudadanía intercultural. En esta discusión está de fondo, efectivamente, la perspectiva de la ciudadanía misma, ya no desde una ciudadanía diferenciada únicamente, sino de una verdadera ciudadanía intercultural con una interacción y mutuo enriquecimiento de los diversos en relación de equidad.

Por último, del análisis del Código de la Democracia (2009) es preciso decir que respecto de los pueblos y nacionalidades y la expresión de sus intereses, tiene la tarea inconclusa. Si bien reitera la calidad de intercultural del Estado, no llega a definir herramientas ni derivaciones para que esta pueda efectivizarse en la diversidad de pueblos. Como hemos reiterado, el hecho de que la soberanía radique en el pueblo, en un Estado que se ha reconocido previamente como diverso, plural e intercultural, amerita herramientas institucionales y legales igualmente acopladas para respetar la soberanía de esa voluntad en la diversidad. Es decir, deben existir los mecanismos electorales lo suficientemente eficaces para lograr este mandato.

Desde nuestra perspectiva es recomendable introducir en la legislación vigente criterios para la participación en equidad, de miembros 
de los pueblos y nacionalidades que habitan en las correspondientes jurisdicciones político-administrativas, en las organizaciones políticas y en las candidaturas a elecciones de asambleístas, particularmente provinciales. Así, por una parte, es necesario generar mecanismos adecuados para reconocer, garantizar y promover el derecho colectivo de los pueblos y las nacionalidades de constituir y mantener organizaciones que los representen (Constitución de 2008, Art. 57, inciso 15), así como, por otra parte, emprender una propuesta de ley de cuotas a favor de los pueblos y nacionalidades indígenas, el pueblo afroecuatoriano y el pueblo montubio, impulsando que las organizaciones políticas, a escala nacional y local, incluyan candidatos de las diversidades culturales de acuerdo a los porcentajes de participación en la población. En este sentido, el CNE puede trabajar en coordinación con la Asamblea Nacional.

Respecto de la lealtad del voto en las poblaciones analizadas, los hallazgos se presentan interesantes y también heterogéneos. Hay que recordar y reiterar, sin embargo, la imposibilidad de generalizar los resultados, dadas las características no probabilísticas del análisis. Por tanto, no son extrapolables a toda la población indígena (tampoco a toda la población shuar, kichwa de la Sierra o kichwa de la Amazonía), ni a toda la población afroecuatoriana o montubia. Se trata de resultados focales y concretos en los cantones estudiados y únicamente en las elecciones de febrero de 2013.

Adentrándonos, entonces, en la información analizada y descrita, podemos señalar en unos casos, y atisbar en otros, la existencia de una diversidad de lealtades en el voto de los pueblos y nacionalidades del Ecuador hacia otros miembros que se autoidentifican como tales, mediatizadas, eso sí, por un amplio abanico de factores ligados al contexto político, socioeconómico y cultural en el que se produjo el ejercicio electoral.

Contextualizado esto, quienes mayor lealtad habrían tenido en esta elección son los cantones indígenas del estudio y, entre ellos, el caso con mayor adhesión a sus representantes en los tres niveles, presidencial, de 
asambleístas nacionales y de asambleístas provinciales, fue el de Taisha en Morona Santiago, seguido de Arajuno y Guamote. El cantón con menor fidelidad en esta elección a sus representantes como pueblo sería Salitre.

Siguiendo esta lógica, partimos de la revisión pormenorizada de los cantones con altos porcentajes de población que se autoidentifica como indígena (Taisha, Arajuno y Guamote) y observamos que, si bien se producen relaciones de lealtad en los tres ejemplos, es preciso mencionar una dinámica muy diferente entre los dos cantones pertenecientes a la Amazonía, y todavía más entre estos y aquel ubicado en la región Sierra.

Los resultados nos hablan de una alta fidelidad por parte de los sufragantes de Taisha, en Morona Santiago, a los candidatos indígenas de la alianza MUPP-MPD en los tres niveles de votación: presidencial, asambleístas nacionales y asambleístas provinciales. Desde nuestro punto de vista, esta fuerte adhesión responde tanto a la identificación de la población con los asambleístas propuestos, con quienes comparten la nacionalidad shuar, concretamente Diana Atamaint y Pepe Acacho, como con el programa político de la Unidad Plurinacional de las Izquierdas, de manera particular por la presencia de Pachakutik. Sin embargo, este soporte recibido en Taisha no se generalizó en la provincia de Morona Santiago, reduciendo su posible repercusión en el escrutinio final y en el acceso a la Asamblea de Atamaint. Este resultado evidencia que el método de asignación de escaños no es lo suficientemente proporcional respecto de la voluntad de los pueblos y nacionalidades, particularmente en el caso shuar de Taisha; y no porque Atamaint no haya alcanzado el Legislativo. También sorprende que Lourdes Tibán resulte la aspirante a asambleísta nacional más votada pese a ser indígena serrana, y que la candidata de nacionalidad shuar, Diana Atamaint, sea la candidata que le sigue, aún ocupando un puesto inferior en el orden de la papeleta. Ello obedece, en primer lugar, a que hubo una intensa tendencia al voto por todos los candidatos de una sola lista, razón por la cual Tibán que era la primera en la lista, logró el mayor número de votos válidos; y 
después, que Atamaint, quinta en la lista, tuvo una fuerte adhesión de voto personalizado quedando la segunda en la votación por candidato. De cualquier forma, en este cantón se denota claramente una lealtad en el voto hacia los candidatos de su identidad étnica y al proyecto político de la Alianza Plurinacional de las Izquierdas (MUPP-MPD).

En el cantón Arajuno, Pastaza, también se produce un respaldo deliberado a los aspirantes indígenas que formaron parte de las candidaturas para asambleístas nacionales y provinciales; esto tanto a Pachakutik que obtuvo el apoyo mayoritario en ambas escalas de votación, como de PAIS. No obstante, los resultados para la elección de la Presidencia de la República reflejaron un voto muy segmentado, que daba por vencedor al binomio Gutiérrez-Boyes del PSP. Este dato no hizo sino levantar otra hipótesis, correlativa al análisis, que debería abordarse con profundidad en una investigación específica. Se trata de la percepción del candidato Lucio Gutiérrez como amazónico por sus lazos personales y familiares con esta región del Ecuador. Entra pues a escena un elemento adicional en la conformación de la lealtad, la calificación de un candidato como propio, de nuestra región al margen de su autoidentificación étnico-cultural, tal vez incluso independientemente de su agrupación política. Como ya mencionamos anteriormente, fue la alianza MUPP-MPD la fuerza más votada para la elección de los niveles del Legislativo en Arajuno.

Otro ejemplo de la complejidad en la fidelidad al voto indígena es el cantón Guamote, provincia de Chimborazo. De una tradición paradigmática en cuanto a la participación política y la elección de indígenas, muestra tendencias divergentes de lealtad entre los niveles de votación presidencial, asambleístas nacionales y asambleístas provinciales. Y es que, si bien PAIS y no el histórico Pachakutik es el vencedor en todos ellos, esta victoria contempla ciertos detalles dignos de ser rescatados. En primer lugar, la candidatura presidencial de PAIS, obtiene el respaldo de casi la mitad de los sufragantes. De igual manera, los asambleístas más votados pertenecen a este movimiento político, produciéndose, como ya resaltamos en el análisis previo, una dinámica de apoyo es- 
pecífico al candidato indígena de la lista de PAIS: Carlos Viteri Gualinga. Finalmente, la propuesta de este movimiento para asambleístas provinciales también resultó ganadora, aunque cabe destacar que esta se realizó en Chimborazo en coalición con Pachakutik contando en su lista con aspirantes indígenas, como fue el caso de Rosa Elvira Muńoz, y se tradujo en dos curules en la Asamblea Nacional. Asimismo, pese a no obtener escaño, otros candidatos indígenas como Pedro Curichumbi de MAY fueron ampliamente respaldados, llegando, finalmente, a quedar como el tercero más votado en todo el cantón.

La complejidad con la que se presenta la posible adhesión o no al voto indígena en Guamote debe observarse considerando otros factores del contexto. Parece evidente la fidelidad a PAIS, aparte de la presencia o no de postulantes indígenas en su candidatura presidencial y en su candidatura para asambleístas nacionales; pero la coyuntura de alianza entre este partido y Pachakutik, precisamente en la escala provincial del sufragio, impide resolver con claridad qué hubiera pasado de no haberse producido la coalición. Finalmente, de ser PAIS el movimiento más votado al margen de la composición de su lista, se hablaría de un cambio radical en la tendencia del voto de Guamote, siendo los próximos comicios para autoridades seccionales una interesante oportunidad para confirmarlo.

Respecto del caso analizado del pueblo afroecuatoriano de San Lorenzo, cantón esmeraldeño con más del $72 \%$ de población afrodescendiente, encontramos una práctica de adhesión en el voto distinta y significativa. Si recordamos los resultados electorales de este cantón, PAIS fue el claro vencedor pese a no contar en las listas propuestas con candidatos afrodescendientes y de existir, en otras listas, aspirantes que sí lo eran y que no fueron favorecidos, como Marcia Caicedo en el binomio presidencial con Alberto Acosta. Sin embargo, la postulación como Asambleísta nacional de Iván Hurtado, afamado futbolista afroecuatoriano y esmeraldeño, registró una amplia predilección entre los sufragantes del cantón. Todo ello deviene en la conclusión de una sólida preferencia al proyecto de PAIS, de forma autónoma a sus candidatos, pero además, de la consideración de ingredientes alternativos en 
la construcción de la lealtad al voto entre los afroecuatorianos de San Lorenzo, además de la pertenencia étnica: la identificación provincial y, sobre todo, la trascendencia de las figuras futbolísticas, los héroes del deporte nacional, como es el caso que nos ocupa. Es decir, queda en este ejemplo específico la pregunta de cuál es el motivo para la mayor adhesión y lealtad respecto de Hurtado: su pertenencia al pueblo afroecuatoriano, su pertenencia a la provincia de Esmeraldas, el ser una figura histórica del balompié ecuatoriano, o todas complementariamente. Por otra parte, respecto del método de asignación de escaños, cabe resaltar que Hurtado, a pesar de una gran fidelidad a su candidatura, llega a colocarse únicamente como el segundo más votado luego de Gabriela Rivadeneira, que es improbable que tenga un reconocimiento de parte de la población de San Lorenzo como figura política o que haya generado, por tanto, algún nivel de lealtad en el sufragio. Nuevamente, este fenómeno revela el voto por todos los candidatos de una sola lista en gran medida y, al mismo tiempo, el apoyo personalizado al candidato afroesmeraldeńo Iván Hurtado.

Finalmente en el cantón montubio Salitre, en Guayas, se descubre una dinámica del voto que, a priori, parecería ser independiente de cualquier fidelidad de filiación étnico-cultural, en virtud de un apoyo mayoritario e indiscutible a PAIS, tanto para la Presidencia de la República, como para la Asamblea Nacional, sin candidatos específicos de autoidentificación montubia entre sus aspirantes, salvo el suplente de Marcela Aguiñaga. Sin embargo, esto podría tener otra lectura si consideramos que algunas organizaciones montubias realizaron no solo una labor de promoción de la candidatura de PAIS, sino que la legitimaron.

Como ya avanzábamos en la introducción de este artículo, el análisis de los datos y estas conclusiones, más allá de reflejar la diversidad en las fidelidades del voto de pueblos y nacionalidades, propician un paso más en la reflexión sobre los avances en el cumplimiento de los derechos colectivos. Advertimos cómo las normas que garantizan y las herramientas que han de viabilizar la representatividad de los pueblos y nacionalidades del Ecuador entran en profunda contradicción. Si 
bien hoy los pueblos y nacionalidades indígenas, pueblo afrodescendiente y pueblo montubio gozan de marcos teóricos que favorecen su autodeterminación y participación política, fruto de un largo recorrido de reivindicaciones y logros constitucionales, los mecanismos para su puesta en práctica adolecen de incoherencia. Un buen ejemplo de ello es el sistema electoral actual basado en el método de divisores continuos ( $D^{\prime}$ Hondt) que limita la alternativa del voto personalizado múltiple al no guardar este un valor equivalente a la opción de voto por una sola lista. Ello complica las posibilidades de representación de los candidatos de la diversidad cultural, condicionados por la lógica de un sistema de votación que privilegia a unos candidatos frente a otros, con relación a la posición que ocupen en una papeleta. Eso explica claramente el porqué una indígena kichwa de la Sierra, de Cotopaxi, gana en el territorio amazónico a pesar del apoyo que los candidatos locales reciben individualmente: Atamaint en Taisha y Viteri en Pastaza.

De todo ello surge nuestra propuesta. Alineados al principio de interculturalidad contemplado en la Constitución, y también a la participación ciudadana y a la necesaria acción afirmativa para promover la equidad y la representatividad de las diversas voluntades e intereses que se expresan en la sociedad, seleccionando y nominando a candidatos para estos puestos electivos, deberíamos como país atrevernos a promover una normativa que garantice y fomente el derecho colectivo de los pueblos y las nacionalidades de constituir y mantener organizaciones que los representen en el marco del pluralismo y la diversidad política. Así como un proyecto de ley de cuotas a favor de los pueblos y nacionalidades indígenas, el pueblo afroecuatoriano y el pueblo montubio. De igual manera, queda por definir, promover (revitalizar si es el caso) y coordinar de manera participativa e institucional los mecanismos y las formas de democracia comunitaria.

Debemos continuar el camino, trabajando para que en el futuro el balance de la acción del presente sea ciertamente positivo, trascendiendo de las declaraciones y principios hacia herramientas congruentes con dichos enunciados. 


\section{Bibliografía}

Kymlicka, Will (1996). Ciudadanía multicultural. Una teoría liberal de los derechos de las minorias. Barcelona: Paidós.

(2009). Las odiseas multiculturales. Las nuevas politicas internacionales de la diversidad. Barcelona: Paidós.

Ministerio de Educación-UNESCO (ed.) (2009). La alfabetización en el Ecuador- Evolución histórica, información actualizada y mapa nacional del analfabetismo. Quito (Disponible en: http://unesdoc.unesco. org/images/0018/001851/185161s.pdf).

Organización Internacional del Trabajo (OIT) (1989). Convenio N.o 169 sobre Pueblos Indigenas y Tribales en Paises Independientes (Disponible en: http://www.oit.org.pe/WDMS/bib/publ/libros/convenio_169_07. pdf).

Salazar Medina, Richard (2011). "Derechos Colectivos e Interculturalidad: hacia la construcción del nuevo Estado". En Interculturalidad y Diversidad. Ariruma Kowii (coord.). Quito: Universidad Andina Simón Bolívar-Corporación Editora Nacional.

Sen, Amartya (2004). "Libertad cultural y desarrollo humano". En La libertad cultural en el mundo diverso de hoy. PNUD, Informe sobre Desarrollo Humano. New York: Ediciones Mundi-Prensa.

Torbisco Cassals, Neus (2009). "La interculturalidad posible: el reconocimiento de derechos colectivos". En Los Derechos Colectivos. Hacia una efectiva compresión y protección. María Paz Ávila y María Belén Corredores (ed.). Quito: PNUD-Ministerio de Justicia y Derechos Humanos.

Normativa y documentos oficiales

CNE (2013). "Resultados electorales 2013 de los cantones Guamote (Chimborazo), Taisha (Morona Santiago), Arajuno (Pastaza), San Lorenzo (Esmeraldas), Salitre (Guayas)". Consulta del 30 de julio de 2013 de la base de datos del Consejo Nacional Electoral: http:// resultados.cne.gob.ec 
Constitución del Ecuador (1967). Asamblea Nacional Constituyente Constitución Politica de la República del Ecuador (1978). Congreso Nacional. Quito (codificada en 1984). R.O. N. 569.

Constitución Politica de la República del Ecuador (1998). Asamblea Nacional Constituyente. Quito. Decreto Legislativo N. 000.

Constitución de la República de Ecuador (2008). Asamblea Constituyente. Ciudad Alfaro.

Decreto Ejecutivo N.o 386. Publicado en el R.O. 86 del 11 de diciembre de 1998.

Decreto Ejecutivo N.o 244. Publicado en el R.O. 48 del 28 de junio de 2005.

Decreto Ejecutivo N.o 1394. Publicado en el Suplemento del R.O. 301 del 6 de abril de 2001.

Ley Orgánica Electoral y de Organizaciones Politicas de la República del Ecuador, Código de la Democracia (2009). Asamblea Nacional. Quito: Suplemento R.O. 578 del 27 abril.

INEC (2010). "Población de Ecuador según autoidentificación y nacionalidad indígena por parroquia”. Consulta del 25 de julio de 2013 de la base de datos del Censo 2010 del Instituto Nacional de Estadísticas y Censos: http://www.inec.gob.ec

Artículos en medios

CRE SATELITAL (2013). "Organizaciones montubias brindan respaldo a candidatos de Alianza PAIS”. 6 de febrero de 2013: www.cre. com.ec/noticia/3022.

El Telégrafo (2012). "Grupo de montubios pide no votar por falsos candidatos". 2 de diciembre de 2012. 